\title{
EL DERECHO CONSTITUCIONAL Y LA CRISIS
}

\author{
ENRIQUE ÁLVAREZ CONDE
}


SUMARIO

I. EL DERECHO CONSTITUCIONAL Y SUS TENSIONES DIALÉCTICAS. II. EL DERECHO CONSTITUCIONAL COMO DERECHO COMÚN. III. LA FALACIA DE LA ACTUAL CRISIS ECONÓMICA. IV. LA GLOBALIZACIÓN Y EL DERECHO CONSTITUCIONAL: A) Una nueva teoría del Estado. B) Un nuevo concepto de representación. C) Una nueva teoría de la Constitución. D) Una radical transformación del sistema de fuentes del Derecho. E) Un nuevo significado de los principios constitucionales y de los derechos fundamentales. F) Un nuevo sistema de relaciones entre los poderes públicos y entre estos y los poderes privados. 


\title{
EL DERECHO CONSTITUCIONAL Y LA CRISIS*
}

\author{
ENRIQUE ÁLVAREZ CONDE \\ Catedrático de Derecho Constitucional \\ Universidad Rey Juan Carlos
}

\section{EL DERECHO CONSTITUCIONAL Y SUS TENSIONES DIALÉCTICAS}

Con carácter general puede afirmarse que el binomio libertad-seguridad es una de las constantes de la Historia de la Humanidad. En efecto, todas las civilizaciones hasta nuestros días han estado sometidas, con distinta intensidad, a la tensión dialéctica existente en dicho binomio, el cual puede ser considerado como uno de los elementos explicativos de su propia evolución histórica. Prueba de ello son los planteamientos que se hicieron en el mundo romano o en los comienzos del Estado liberal. Por eso, no es de extrañar que los diferentes movimientos ideológicos — liberalismo, marxismo, anarquismo...- adoptaran posturas distintas en torno a esta cuestión.

Por su parte, el Derecho, como ciencia del espíritu, y más en concreto el Derecho constitucional, también puede ser considerado desde esta perspectiva dialéctica. Es más, todo el proceso de evolución histórica y conceptual del mismo no es sino una visión determinada de dicha tensión, reflejando los momentos álgidos de aquella ${ }^{1}$.

* El presente trabajo forma parte de un proyecto de investigación, del cual soy investigador principal, que, con el título «Transformaciones del Derecho ante la crisis», financia la propia URJC.

1 Es posible señalar también la existencia de otras tensiones dialécticas, producto de que el Estado Constitucional es la formulación normativa de un concreto modo de producción, el capitalismo. Cfr. C. DE CABO, «Propuesta para un constitucionalismo crítico», Discurso de aceptación del Doctorado Honoris causa de la Universidad de Alicante, 2012. 
Una manifestación de la seguridad la encontramos en el principio monárquico, que elabora unas determinadas categorías dogmáticas justificativas y/o explicativas de la necesidad de garantizar una determinada seguridad, que no representan sino los intereses económicos de una determinada clase social detentadora del poder político. Este principio estará presente durante buena parte de la vigencia del Estado liberal, en el que mantiene sus propias categorías dogmáticas, las cuales continúan siendo fieles a su origen iusprivatista, pues tampoco se hacían necesarias categorías alternativas al no haberse producido una auténtica ruptura en los planteamientos teóricos del proceso de evolución histórica del Estado. El principio monárquico pretende, de este modo, mantener las estructuras tradicionales y, en consecuencia, los medios de dominación existentes, acomodándolos, en la medida de lo posible, a las evoluciones históricas posteriores. Por ello, utiliza unas categorías dogmáticas que tienen una fundamentación clara en épocas pretéritas.

Frente a ello, el principio democrático intentará configurarse como una alternativa, con categorías jurídicas diferentes, aunque no siempre logrará una total independencia conceptual, pues tampoco los elementos de ruptura en dicho proceso histórico son claros y evidentes. Es precisamente este hecho, la falta de categorías dogmáticas radicalmente alternativas a las ya existentes, una de las características de la evolución histórica del Derecho constitucional, sin que ello signifique mantener que el principio democrático es una simple evolución histórica del principio monárquico. En efecto, ahora ya no se trata de justificar los intereses económicos de una determinada clase o grupo social, sino la defensa del interés general, del cual participan todos los poderes públicos, y que sitúa a los individuos en una posición de igualdad. Precisamente por ello, la elaboración de nuevas categorías alternativas presenta un mayor grado de dificultad teórica, que únicamente puede ser superado abandonando la idea de que las normas jurídicas son algo neutral, aséptico, independientes de la realidad social y económica que tratan de normativizar.

Con posterioridad, ambos principios, el monárquico y el democrático, han evolucionado de forma muy diversa. El primero de ellos ha continuado luchando, y en ocasiones lo ha conseguido, por desempeñar un papel semejante al que había tenido en épocas pasadas. Por su parte, el principio democrático se ha limitado a actuar a través de la celebración de elecciones periódicas más o menos competitivas, con una defensa formal del pluralismo, y la creación de un marco normativo configurador de condiciones más o menos adecuadas para un pluralismo político aceptable en aquel momento, interpretando que no eran necesarias otras series de manifestaciones, pues su presencia estaba absolutamente consolidada y el otro principio no representaba ningún peligro o amenaza. Ante este panorama, 
ante esta conformidad propia y/o impuesta por otras circunstancias e intereses, la crisis del propio sistema democrático parecía la crónica de una muerte anunciada.

Por el contrario, el Derecho, y aún más el Derecho constitucional si se quiere, es algo beligerante ${ }^{2}$, combativo, que responde a un determinado planteamiento ideológico, tal y como sucede con los auténticos sistemas democráticos. Pero ello no empece para reconocer que continúan existiendo intereses pretéritos o que surjan otros nuevos, los cuales, los unos y los otros, ya no dispondrán de un camino tan fácil, pues la neutralidad ha desaparecido y la beligerancia impone, necesariamente, más condicionamientos que unos y otros deberán aceptar. Pero además, ello implica que el Derecho constitucional no se inserta exclusivamente en el ámbito del Derecho público, pues lo privado no es ajeno al Derecho constitucional, sino que también forma parte del mismo. Esta es la conclusión más contundente de su consideración como Derecho común y de la concepción de la Constitución como norma suprema de todo el ordenamiento jurídico.

Si queremos profundizar en esta línea de construcción conceptual hay, pues, que alejarse de aquellos planteamientos teóricos que proclaman la neutralidad de la Constitución y del ordenamiento jurídico. Una Constitución neutra, procedimental, es una Constitución inerme, no es una auténtica Constitución. Por ello hay que defender la tesis de que la Constitución crea una democracia militante ${ }^{3}$, cuestión esta que nada tiene que ver con la ausencia de límites materiales expresos a la reforma constitucional y que fue puesta de relieve entre nosotros con motivo del proceso de ilegalización de Batasuna por parte del Tribunal Constitucional, el cual, erróneamente a nuestro juicio, negó la existencia de dicha democracia militante ${ }^{4}$. La Constitución es siempre valorativa, axiológica,

2 C. DE CABO, «Lo viejo y lo nuevo en la crisis económica actual: aspectos jurídicos políticos», en G. CAMARA, Pensamiento crítico y crisis capitalista, Granada, 2010, y «Constitucionalismo del Estado social y Unión Europea en el contexto globalizador», Revista de Derecho Constitucional Europeo, n. ${ }^{\circ} 11,2009$.

3 Sobre la llamada democracia militante, Cfr. K. LOEWENSTEIN, «Militant Democracy y and Fundamental Rights», American Political Science Review, n. ${ }^{\circ}$ 31, 1937; R. BASSET, The Essentials of Parlamentary Democracy, Londres, 1964; E. DENNINGER, «Democracia militante y defensa de la Constitución», en BENDA y otros, Manual de Derecho Constitucional, Madrid, 2001; G. SARTORI, Teoría de la democracia, Madrid, 2000; A. BARRERO, «Reapertura del debate democracia abierta v. democracia militante en la jurisprudencia del Tribunal Europeo de Derechos Humanos», en J.A. MONTILLA (Ed.), La probibición de partidos políticos, Madrid, 2004; A. GONZALEZ ALONSO, «La lealtad constitucional. La Constitución como orden de valores o como procedimiento», Revista de Derecho Político, n. ${ }^{\circ}$ 120, 2003.

4 Cfr. esta cuestión en E. ALVAREZ CONDE, El derecho de partidos, Madrid, 2005; A. TORRES DEL MORAL, «Democracia militante», en la obra colectiva Derecho Constitucional para 
y sus valores no son sino la expresión de las decisiones políticas fundamentales que adopta una determinada comunidad política a través del ejercicio del poder constituyente. Cuando estas decisiones políticas se cambian, cuando estos valores se alteran por otros poderes distintos, cuando el pluralismo político y social pierde su vigencia, el principio democrático experimenta una profunda quiebra, una profunda ruptura, o si se quiere un anquilosamiento, que no supone sino la entrada en acción de nuevo del principio monárquico.

Ahora bien, cuando los llamados sistemas democráticos se agotan en sus propios postulados teóricos, cuando se convierten en incapaces de continuar dando una respuesta coherente a la defensa del interés general ${ }^{5}$, se hace preciso todo un rearme ideológico que conduzca a la elaboración de nuevas categorías dogmáticas y a la transformación de una realidad social, que ha sido nuevamente invadida por el principio monárquico ${ }^{6}$. Es precisamente en este momento cuando se acrecientan las tensiones dialécticas y las impotencias de los actuales

el siglo XXI, Navarra, 2006, tomo I, pp. 209-ss.

5 El interés general no es un simple artificio jurídico abstracto, sino el intento de construcción de una nueva categoría dogmática alternativa a las anteriores. El interés general, al igual que sucedía con la voluntad general de Rousseau, no es la simple suma de los intereses particulares, sino que el mismo se deduce de un proceso de abstracción y objetivación sobre los mismos. Su defensa corresponde al poder público más próximo, por su legitimidad, al poder constituyente. Pero todos los poderes públicos, y en menor medida los poderes privados, participan en su definición sin que nadie, salvo el propio poder constituyente, pueda atribuirse su monopolio. Por ello, y como ya señalara el propio $\mathrm{N}$. BOBBIO, en los sistemas democráticos pueden producirse efectos perniciosos o «perversos, en el sentido de que en el propio seno de las democracias se desarrollan situaciones que la contradicen y amenazan con derrocarlas». Vid. N. BOBBIO, El futuro de la democracia, México, 1994. Sobre el significado del interés general, concepto incluido en nuestro texto constitucional, en la legislación de desarrollo y utilizado por nuestra propia jurisprudencial, cfr., entre otros, E. ALBERTI, «El interés general y las CC.AA. en la Constitución de 1978», Revista de Derecho Político, n. ${ }^{\circ}$ 18-19, 1983; J. BERMEJO VERA, «El interés general como parámetro de la jurisprudencia constitucional», Revista vasca de Administración Pública, n. ${ }^{\circ} 10,1984 ;$ C. VIVER, «Soberanía, autonomía, interés general... y el retorno del jurista persa», Revista vasca de Administración Pública, n. ${ }^{\circ}$ 25, 1990; M. JIMENEZ DE PARGA, «El interés general y la solidaridad entre los españoles, dos principios necesitados de atención», Revista de la Facultad de Derecho de la Universidad Complutense, $n .^{\circ} 21,1997$; M. TEROL, «El interés general, su importancia en el esquema de distribución de competencias entre el Estado y las Comunidades Autónomas», Revista de Estudios Políticos, n. ${ }^{\circ}$ 46-47, 1985.

6 Cfr., a este respecto, P. DE VEGA, «Mundialización y Derecho constitucional: la crisis del principio democrático en el constitucionalismo actual», Revista de Estudios Políticos, n. ${ }^{\circ}$ 100, 1998; M. ARAGON, Constitución y democracia, Madrid, 1989; E.W. BÖCKENFÖRDE, «La democracia como principio constitucional», en Estudios sobre el Estado de Derecho y la democracia, Madrid, 2000; J.J. GOMES CANOTILHO, «El principio democrático. Entre el Derecho constitucional y el Derecho administrativo, Revista de Derecho Constitucional Europeo, n. ${ }^{\circ}$ 11, 2009. 
planteamientos teóricos. Y este parece ser el momento actual en que nos encontramos, dada la crisis del Estado Social de Derecho, la cual es debida a una multiplicidad de causas, ya suficientemente explicadas por la doctrina.

\section{EL DERECHO CONSTITUCIONAL COMO DERECHO COMÚN}

La existencia de un Derecho común es algo consustancial al proceso de normativización de las relaciones sociales ${ }^{7}$. El mismo debe ser entendido como aquél que proporciona respuestas globales y no sectoriales, lo cual corresponde a otras disciplinas jurídicas, a los problemas planteados. Por ello, su estructura normativa es distinta, produciéndose, a diferencia de lo que sucede en otras disciplinas jurídicas, una especie de prevalencia de los principios sobre las reglas ${ }^{8}$. Ello no quiere decir que las diferentes disciplinas jurídicas puedan ser clasificadas en función de su condición de normas principiales o normas que únicamente contienen reglas. En todas ellas coexisten ambos tipos de estructuras normativas. Lo que sucede es que en el Derecho Constitucional predominan las normas principiales, lo cual es coherente con su condición de Derecho común del ordenamiento jurídico. Por su parte, las reglas unas veces, aunque las menos, forman parte también del Derecho constitucional y, en otras ocasiones, se incorporan a otras disciplinas jurídicas, tanto de Derecho público como de Derecho privado.

En un primer momento, la condición de Derecho común del ordenamiento jurídico va a corresponder al Derecho civil, que la ostentará durante varios siglos, tanto por razones históricas como conceptuales. En efecto, la desaparición del Derecho público romano y el mantenimiento, por razones de seguridad jurídica, del Derecho privado, hizo que éste, especialmente después de la recepción del Derecho justinianeo, se convirtiese en fuente directa dentro del proceso de construcción de un nuevo Derecho público. Determinadas categorías dogmáticas como la de contrato, mandato, etc..., fueron utilizadas, al principio en sus propios términos, para fundamentar la teoría del vasallaje o el propio concepto de representación medieval. Ello es explicativo también de un momento histórico determinado en el cual las relaciones inter privatos agotaban toda la realidad social.

Por ello, no es de extrañar que el nuevo Derecho público que va surgiendo se sustente sobre bases iusprivatistas, donde el principio monárquico agota todo el

7 R. FERNANDEZ CARVAJAL, «Notas sobre el Derecho constitucional como nuevo derecho común», Anuario de Derecho Constitucional y Parlamentario, n. ${ }^{\circ}$ 1, 1989, p. 44.

8 Cfr. V. CRISAFUlLI, La Costituzione e le sue disposición di principio, Milano, 1953; G. ZAGREBLESKY, El derecho dúctil. Ley, derechos, justicia, Madrid, 2003, pp. 109-ss. 
sistema de relaciones sociales, que son las únicas realmente existentes o, al menos, las únicas reconocidas normativamente. Así, categorías dogmáticas propias del Derecho privado son utilizadas para el inicio de una tímida reconstrucción del nuevo Derecho público. Y este proceso continúa hasta la llegada del Estado liberal. Tan solo determinados hitos históricos, como pueden ser la idea de Ley Fundamental, el protestantismo y su defensa de la libertad religiosa, el mercantilismo en su condición de primer movimiento teórico auténticamente intervencionista, los fisiócratas y su concepto de la opinión pública y, en alguna medida, las teorías pactistas, representan elementos aislados de ruptura con este proceso, sin perjuicio de reconocer que también los mismos, o al menos algunos de ellos, poseen un fundamento iusprivatista.

Llegados a este punto se nos plantea la cuestión de si la llegada del Estado liberal y los acontecimientos revolucionarios suponen o no un cambio en la titularidad del Derecho común, pasando el Derecho constitucional a desempeñar el papel que hasta entonces había correspondido al Derecho privado. La respuesta no es fácil, pues nos encontramos con argumentaciones contradictorias. Por un lado, no existen razones históricas que lo avalen, pues las relaciones de producción en el liberalismo son esencialmente medievales, suponiendo tan sólo un cambio en la titularidad de la clase social que detenta el poder político. Pero si bien ello es cierto, también lo es que esta nueva clase social, la burguesía, detentadora ahora del poder político, tiene un planteamiento radicalmente diferente, basado en el contractualismo como premisa histórica revolucionaria. En efecto, el burgués es un ser utópico, platónico, idealista ${ }^{9}$, que pretende no sólo establecer un modelo de dominación política sobre otras clases o grupos sociales, sino también, y de modo preferente, extender a toda la población su carácter burgués. Es decir, la lucha de clases no es el ideal burgués, sino la existencia de una sola clase social burguesa, idílica, dando así continuidad al Estado de naturaleza lockeano.

Al propio tiempo, el Estado liberal, y ello sí que supone una reacción ideológica y conceptual significativa, establecerá un tríptico ideológico: Libertad, Igualdad y Fraternidad, del cual únicamente desarrollara, y de forma parcial, el primero de ellos ${ }^{10}$. Los otros dos serán objeto de momentos históricos posteriores o incluso puede considerarse que se encuentran, en cierto modo, aún pendientes

9 W. SOMBART, El burgués: contribución a la bistoria espiritual del hombre económico moderno (texto originario de 1913), Madrid, 1993.

10 Sobre el proceso de desconstitucionalización del propio constitucionalismo en el S. XIX, vid. P. CRUZ VILLALÓN, «Formación y evolución de los derechos fundamentales», Revista Española de Derecho Constitucional, n. ${ }^{\circ}$ 25, 1989. Cfr., desde otra perspectiva, M. BOVERO, Una gramática de la democracia, Madrid, 2002, para quien la lógica del mercado es una lógica de la alienabilidad, pues la distribución desigual de los medios vuelve desigual el valor de la libertad. 
de una normativización adecuada. Con ello se inicia, aunque sea inconscientemente, que no quiere decir de forma ingenua, la idea de un Derecho constitucional principial, cuyas normas han de convertirse en punto de referencia de todo el ordenamiento jurídico, el cual no es sino un desarrollo de aquellas.

Y para ello, y esta es una razón más que justifica el cambio de titularidad del Derecho común a favor del Derecho constitucional, se crea el concepto liberal de Constitución (art. 16 de la Declaración de Derechos del Hombre y del Ciudadano), con el reconocimiento, al menos formal, de toda una serie de derechos a todos los individuos, y con la adopción de una serie de técnicas (principio de división de poderes, constitución normativa en el modelo norteamericano) para llevar a cabo ese planteamiento utópico e idílico, que no es muy diferente en los distintos procesos revolucionarios de la época (ingles, norteamericano y francés). Es decir, se inicia el camino para la construcción de categorías dogmáticas alternativas, que no suponen necesariamente el abandono total de las anteriores. De este modo, se está dando entrada, paulatinamente, eso sí, al principio democrático.

Este planteamiento idílico y utópico quiebra con los primeros ataques antisistema al Estado liberal a mediados del siglo XIX (Manifiesto comunista, la Comuna de Paris, etc...) que, si bien son superados por aquél, dando lugar al periodo de mayor estabilidad política (último tercio del siglo XIX), suponen un cambio importante en tanto la aparición de dichos movimientos antisistema, y consiguiente desaparición del monopolio liberal burgués, se traducen en el abandono de ese planteamiento utópico y la adopción de medidas más contundentes y serias para garantizar las conquistas revolucionarias liberales. Además, en esta época se produce la aparición de toda una nueva dogmática, debida en gran parte a los juristas alemanes, que a la postre, y desprovista de los condicionamientos políticos que propiciaron su aparición, supondrá una importante aportación a la idea del Derecho constitucional, o del Derecho público si se quiere, como Derecho común. Conceptos tales como la personalidad jurídica del Estado o la propia noción de derecho público subjetivo, contribuirán decididamente a ello, intentando la creación de una dogmática propia y alternativa a la ofrecida por los planteamientos iusprivatistas, de los cuales pretenden independizarse sin manifestar un propósito decidido por recuperar el ideal o los propios principios revolucionarios.

Por otro lado, la aparición de los llamados Estados de emergencia ${ }^{11}$, supone la adopción de mecanismos de defensa del propio Estado liberal, impensables en

11 Sobre los estados de emergencia y sus implicaciones en el desarrollo del constitucionalismo, Cfr. H. FIX-ZAMUDIO, «Los estados de excepción y la defensa de la Constitución», Boletín Mexicano de Derecho Comparado, n. ${ }^{\circ}$ 111, 2004; P. CRUZ VILLALÓN, Estados excepcionales y suspen- 
los primeros momentos de su instauración; mecanismos que pasan al ámbito específico del Derecho constitucional, acentuando de este modo su condición de Derecho común. Es decir, las situaciones de emergencia, con la suspensión y/o restricción de los derechos y libertades, la militarización de los poderes públicos y de la propia sociedad civil, etc..., se van a convertir en algo esencial en los momentos posteriores del Estado liberal, alterando su primitiva concepción ideológica, que, como es sabido, no consideraba necesaria la existencia de los mismos, pues sus propios planteamientos teóricos eran más que suficientes para la defensa del «ideal burgués». Ahora bien, ello tiene un carácter provisional, transitorio, razón por la cual a los liberales les resulta imposible preveer las crisis, las emergencias, pudiendo tan sólo regularlas cuando éstas ya se han producido. Pero lo importante es señalar que en los supuestos de crisis, de emergencia, se va a acudir al Derecho constitucional para que otorgue una respuesta, lo que es claramente revelador de su posición como Derecho común y principial, sin que ello impida seguir acudiendo a categorías dogmáticas propias del Derecho privado, como pueden ser las cláusulas rebus sic stantibus o pacta sunt servanda ${ }^{12}$. No debemos olvidar que, a la postre, el Derecho constitucional, la propia Constitución, son un Derecho, y una norma, de la crisis. Ello, por otra parte, nos permite rechazar las tesis que señalan que en tiempos de crisis no es conveniente legislar, remitiéndonos a momentos posteriores, cuando aquella haya pasado; momentos en los cuales, sin embargo, ya no se siente la necesidad de hacerlo.

El Estado liberal, con las características anteriormente apuntadas, continuó su curso hasta la I Guerra Mundial. Su final supone el inicio de un nuevo periodo, de un nuevo ciclo constitucional, el periodo de entreguerras, caracterizado, por lo que a nosotros nos interesa, por un cambio sustancial en los planteamientos ideológicos y dogmáticos del Estado liberal. En este sentido se produce un alteración conceptual importante que afecta a la propia teoría de la Constitución, a la vigencia de los derechos y libertades (con la aparición de nuevas generaciones de derechos), y al sistema de relaciones entre los diferentes poderes públicos. Y es que

sión de garantías, Madrid, 1984; J.M. GOIG MARTÍNEZ, «La defensa política de la Constitución. Constitución y estados excepcionales», Revista de derecho UNED, n. ${ }^{\circ} 4-5,2009$; J.M. CASTELLS ARTECHE, «Inter arma silent leges: notas sobre el derecho de excepción», Revista Vasca de Administración Pública, n. ${ }^{\circ}$ 87-88, 2010; J.M. LAFUENTE BALLE, «Los Estados de alarma, excepción y sitio», Revista de Derecho Politico, n. ${ }^{\circ} 31$, 1990; E.M. BRU PERAL, «Estados de alarma, excepción y sitio», Derechos y libertades, n. ${ }^{\circ}$ 7, 1999; M. CARBONELL SÁNCHEZ, «Neoconstitucionalismo y derechos fundamentales en tiempos de emergencia», Estudios constitucionales. Revista del Centro de Estudios Constitucionales, n. ${ }^{\circ} 1,2008$.

12 G. DE VERGOTINI, Guerra e Costituzione. Nuovi conflitti e sfide alla democracia, Bologna, 2004. 
parecía necesario dar una respuesta nueva a los movimientos ideológicos antiliberales (marxismo y fascismos) que conviven con el movimiento liberal, adaptándose a las nuevas circunstancias y ofreciendo elementos teóricos más sólidos.

Pero al propio tiempo se va a producir la primera crisis seria del sistema capitalista. Es el crack de 1929, que en determinados aspectos nos recuerda a la actual crisis, pues no sólo es una crisis económica, sino también una crisis de valores que se dilucidara en los campos de batalla a partir de 1939. Una crisis caracterizada, por lo demás, por su internacionalización, apareciendo un nuevo fenómeno que algunos han denominado el Derecho constitucional internacional ${ }^{13}$.

La II Guerra Mundial supuso, entre otras cosas, la desaparición de los movimientos fascistas que, no obstante, perdurarán en algunos países como el nuestro. Ya sólo quedan, pues, dos grandes modelos ideológicos: el nuevo Estado constitucional y el Estado marxista, enfrentados y, a su vez, relacionados también entre sí y con influencias mutuas, que para algunos, especialmente tras la desaparición de la URSS, supondrá la existencia de un pensamiento único. Ello va a implicar una menor beligerancia en los planteamientos ideológicos, llegando incluso a proclamarse el fin de las ideologías. Sin embargo, este planteamiento desaparece pronto, pues cuestiones tales como los nuevos procesos de integración supranacional, el nuevo sistema de protección multinivel de los derechos, el proceso de globalización e internacionalización de las relaciones sociales, y un largo etcétera, ponen de relieve la necesidad de proceder a toda una «reconstitucionalizacion» de diferentes cuestiones y temas que habían sido abandonados a la acción de otras normas jurídicas, y también de otras disciplinas jurídicas. Surge, de este modo, un nuevo Derecho constitucional, que debe dotarse de nuevas categorías dogmáticas, estableciendo un nuevo sistema de relaciones normativas e institucionales.

13 Vid. entre la doctrina, G. AGUILAR CAVALLO, «La internacionalización del Derecho constitucional», Estudios constitucionales: Revista del Centro de Estudios Constitucionales, n. ${ }^{\circ}$ 1, 2007; D. VALADÉS, «Visión panorámica del constitucionalismo en el siglo XX», Revista de derecho constitucional europeo, n. ${ }^{\circ}$ 12, 2009; J.L. CABALLERO OCHOA, «El derecho internacional en la integración constitucional. Elementos para una hermenéutica de los derechos fundamentales», Revista Iberoamericana de Derecho Procesal Constitucional, n. ${ }^{\circ}$ 6, 2006; M.A. NÚÑEZ POBLETE, «Introducción al concepto de identidad constitucional y su función frente al derecho supranacional e internacional de los derechos de la persona», Ius et praxis, n. ${ }^{\circ} 2,2008$; M.J. RISSO FERRAND, «Interrelación entre el Derecho constitucional y el Derecho internacional de los derechos humanos», Anuario Iberoamericano de justicia constitucional, n. ${ }^{\circ}$ 16, 2012; M.I. del TORO HUERTA, «La apertura constitucional al derecho internacional de los derechos humanos en la era de la mundialización y sus consecuencias en la práctica judicial», Boletín Mexicano de Derecho Comparado, n. ${ }^{\circ}$ 112, 2005; y la obra colectiva coordinada por A. PETERS, M.J. AZNAR GÓMEZ, I. GUTIÉRREZ GUTIÉRREZ, La constitucionalización de la comunidad internacional, Valencia, 2010. 
A la situación anteriormente descrita no le resultan ajenos, por lo demás, nuevos problemas, que se expresarán en la segunda crisis económica del sistema capitalista: la crisis de 1973, radicalmente distinta de la anterior. La misma, y otros acontecimientos como el de mayo del 68 francés, permitirán constatar cómo el nuevo Estado social parece incapaz de dar solución a los problemas planteados, pues las categorías dogmáticas acuñadas se han vuelto obsoletas. Se produce, de este modo, el inicio de un pensamiento crítico y de un nuevo constitucionalismo ${ }^{14}$, que no sólo revela la necesidad de nuevas categorías dogmáticas, sino que pone de relieve la propia crisis del sistema y la necesidad de nuevos planteamientos ideológicos, que parecen introducirnos en una nueva etapa en la evolución del constitucionalismo contemporáneo, como consecuencia de las transformaciones experimentadas por el Estado como forma histórica del poder político.

El llamado neoconstitucionalismo pretende configurar unas nuevas categorías dogmáticas, producto de los cambios estructurales producidos, con un carácter global y general y que vaya más allá de las realidades de los actuales Estados constitucionales en el mundo occidental ${ }^{15}$, poniendo de relieve la sustantividad y materialidad de los textos constitucionales, las prácticas jurisprudenciales innovadoras, que a veces implican parámetros de interpretación novedosos, y los desarrollos teóricos superadores de una mera descripción del fenómeno jurídico. Se abandonan así los elementos descriptivos, que pasan a ser sustituidos por otros de carácter prescriptivo. En suma, se trata de superar el positivismo clásico y efectuar una nueva construcción teórica del Derecho y del ordenamiento jurídico, aportando soluciones nuevas a los problemas actualmente planteados.

Este es el momento en que nos encontramos en la actualidad, reavivado por la actual crisis económica que se inicia en el año 2008, y que implica todo un cambio de mentalidad. En efecto, ahora las crisis no parecen tener un carácter cíclico, relativamente fácil de superar por el propio sistema. Nos encontramos ante una crisis de legitimidad del mismo, lo cual implica la necesidad de hallar un modelo alternativo al actual, fundamentado en bases ideológicas y concep-

14 M. CARBONELL (Ed.), Teoría del neoconstitucionalismo, Madrid, 2007; C. BERNAL PULIDO, «El neoconstitucionalismo a debate», Temas de Derecho Público, n. ${ }^{\circ} 76$, Bogota, 2006; E. MEIER GARCIA, «(Neo)Constitucionalismo e internacionalización de los derechos», Universitas, n. ${ }^{\circ}$ 15, 2012; M. ATIENZA, «Constitucionalismo, globalización y derecho», en M. CARBONELL y L. GARCIA JARAMILLO (Eds), El canon constitucional, Madrid, 2010; R. AVILA SANTAMARIA: Neoconstitucionalismo y Sociedad, Quito, 2008; G. CAMARA VILLAR (Ed. y Coord.), Pensamiento crítico y crisis capitalista. Una perspectiva constitucional, Granada, 2010.

15 Cfr. a este respecto, P. HABERLE, El Estado constitucional, Buenos Aires, 2007. 
tuales diferentes. Y es que resulta imposible negar que los supuestos sean distintos, que el marco estatal resulte insuficiente pero a la vez imprescindible, y que existe una elevada internacionalización de la propia crisis, etc. Es decir, se trata de una crisis económica radicalmente distinta de las anteriores, que no puede ser asumida por el sistema si éste no cambia desde sus raíces de forma radical, transformándose en otro muy distinto al actual.

Parece llegado el momento de que el Derecho constitucional, como Derecho común a todo el ordenamiento jurídico, y por ser un Derecho de la libertad, de la igualdad y de la solidaridad (fraternidad revolucionaria) ${ }^{16}$, sea el que ofrezca las respuestas necesarias, evitando que éste papel sea cumplido por otros sectores del ordenamiento jurídico, más propicios, además, a la vigencia del principio monárquico y a proporcionar soluciones sectoriales a la crisis. Se trata, en suma, desde la perspectiva misma del Derecho constitucional, de que el principio monárquico no vuelva a convertirse en elemento legitimador y fundamentador del sistema perdiendo éste toda su virtualidad y potencialidad, y de que el principio democrático alcance su plena vigencia y actualidad real y efectiva, abandonando los planteamientos puramente formales y los ámbitos de aplicación de carácter sectorial. Ese principio democrático debe convertirse, como elemento legitimador del sistema que es, en un límite material al propio proceso de reforma constitucional, pues ni siquiera el poder constituyente puede hacerlo desaparecer sin perder su condición de poder constituyente democrático. Y sí bien es cierto que podría hacerlo en cuanto no cabe negarle su condición de poder originario, ilimitado y creador de un orden nuevo, el resultado sería la desaparición de su carácter democrático y, previsiblemente, de la titularidad que corresponde a toda la ciudadanía. Sería un poder constituyente en manos de un grupo social determinado, o de un individuo concreto, cuyos ejemplos históricos son bien conocidos.

Hoy día, los poderes invisibles de que hablara Bobbio $^{17}$, se han vuelto visibles y protagonistas, contribuyendo a la privatización de lo público y alejando al Estado de su condición de punto de convergencia y de su función de dirección y solución de los conflictos existentes, los cuales, en ocasiones, se sustraen al

16 Resulta evidente que el Estado liberal es un Estado insolidario, y que la solidaridad misma es un principio básico del Estado social. Cfr. a este respecto, C. DE CABO, Teoría constitucional de la solidaridad, Madrid, 2006. Asimismo, P. HABERLE, Libertad, Igualdad, Fraternidad, Madrid, 1998; F. GIUFFRÈ, La solidarietà nel ordinamento costituzionale, Milano, 2002. Otros autores (J. RAWLS) han hablado del principio de la justicia, con la finalidad de que la persecución de la igualdad encuentre el vehículo adecuado del cambio dinámico y se produzca una adecuación entre la libertad y la igualdad. Cfr., a este respecto R. MATE, Tratado de la injusticia (Pensamiento crítico. Pensamiento utópico), Barcelona, 2011.

17 N. BOBBIO, El futuro de la democracia, México, 1997. 
ámbito de una regulación normativa. Frente a ello, sin embargo, hay que sostener la responsabilidad que recae en los poderes públicos, pues deben modular las reglas del mercado, compensando los desequilibrios existentes, y evitando que la crisis de legitimación se convierta en una crisis de identidad ${ }^{18}$. Y ello únicamente es posible realizarlo a través de la constitucionalización de lo privado, pues el Derecho constitucional es el sector del ordenamiento jurídico que encierra una mayor potencialidad transformadora de la realidad social. Ello ha de suponer, en resumidas cuentas, la posibilidad real y efectiva de introducción de las categorías dogmáticas públicas en el ámbito privado.

El espacio público y el privado no representan dos compartimentos estancos, dos líneas paralelas, que actúan sin ningún tipo de relación entre si. Y por ello se hace difícil sostener que respondan a categorías dogmáticas diferentes y contradictorias. Si hay un Derecho principial, si lo privado también está dentro de la Constitución, sin la posibilidad de sustraerse a la misma, las categorías dogmáticas deben ser únicas para ambos espacios, para el público y para el privado. La propia vigencia del principio democrático es consustancial a la difuminación de ambas esferas, pues el demos está plenamente habilitado para adoptar decisiones sobre cualquier ámbito que considere apropiado ${ }^{19}$.

Pero todo lo anterior no impide que las diferentes ramas del ordenamiento jurídico, según sea su mayor incidencia en uno y otro espacio, dispongan de una autonomía conceptual propia, con la consiguiente elaboración de categorías dogmáticas y de técnicas normativas distintas, más adaptadas a la realidad social que pretenden normativizar. Por esta razón, la interpretación de los diferentes sectores del ordenamiento, si bien debe tener un tronco común, radicado en el Derecho principial, puede utilizar técnicas diversas en tanto la adecuación de la norma a la realidad no tiene por qué ser necesariamente la misma. Pensemos, a

18 M. WEBER, Economía y Sociedad, México, 2003.

19 Desde la convicción de que las modernas democracias representan la confluencia de tres corrientes (democrática, liberal y republicana) sostiene O"DONNELL que, a diferencia del principio democrático, el liberalismo (según el cual hay ciertos derechos que no se pueden invadir bajo ningún concepto), y el republicanismo (para el que el desempeño de actividades públicas es una actividad dignificante que puede implicar el sacrificio de lo privado) establecen un corte dualista entre lo público y lo privado con límites que han de reconocerse de forma rigurosa. De este modo, la tradición liberal entiende que es en el área privada donde la vida humana se desarrolla de forma plena, y de ahí su ambigüedad hacia el Estado y hacia la esfera pública, que garantizan las libertades con suficiente poder al tiempo que se trata de prevenir posibles invasiones sobre las mismas por parte de aquellos. Y por su parte, para la corriente republicana, de carácter elitista, quienes basan su derecho a gobernar en la superioridad de sus virtudes despreciarían a quienes se dedican a los menesteres privados. Cfr. G. O”DONNELL, Disonancias. Críticas democráticas a la democracia, Buenos Aires, 2007, pp. 88-ss. 
modo de ejemplo, en el diferente significado de la analogía en el Derecho público o en el Derecho privado.

Por todo lo anterior, resulta necesario efectuar una apuesta contundente y clara en favor de la constitucionalización de nuevos - y antiguos- espacios públicos y privados. No se trata, no obstante, de petrificar determinados sectores sociales o diferentes ámbitos, sino de elevar al contenido de nuestra norma suprema aquellas nuevas decisiones políticas fundamentales que deben adoptarse para ofrecer una solución a los nuevos problemas planteados. De otro modo, con los actuales contenidos constitucionales, con las actuales regulaciones normativas, seremos incapaces de ofrecer estas soluciones, permitiendo, a la vez, que otros poderes, los poderes privados, por vías legales o simples actos de hecho, procedan a la asunción de los mismos.

El derecho principial, la Constitución en suma, no sólo tiene como misión la concreción de las decisiones políticas fundamentales, sino que también debe contener los mecanismos necesarios, en éste caso reglas, para permitir la defensa y garantía de las mismas y, al propio tiempo, dotarse de la flexibilidad suficiente, sin abandonar aquellas, para permitir la incorporación de nuevas decisiones políticas fundamentales, que siempre han de ser decisiones del poder constituyente y no de los poderes constituidos, y mucho menos de los poderes privados, propios o foráneos. La idea de un Derecho constitucional principial, la aceptación de la Constitución como norma jurídica suprema, implica necesariamente la intervención periódica del poder constituyente y no la ocultación del mismo o el ejercicio de sus funciones por parte de los poderes constituidos, incluido el poder de reforma, pues éste también es un poder constituido. Es cierto que estos poderes constituidos pueden modificar aspectos de la propia Constitución, pero no sus partes esenciales, sus principios configuradores. Ello únicamente es competencia del auténtico poder constituyente, que implica necesariamente la intervención directa de la ciudadanía, del demos.

Los principios constitucionales no suelen estar, como tales, positivizados en preceptos concretos, sino que su existencia se induce de otros mandatos normativos, convirtiéndose, de éste modo, en la esencia de la Constitución. Toda norma fundamental responde a una serie de principios, que normalmente se convierten en límites materiales expresos al proceso de reforma constitucional, lo que no sucede en nuestro ordenamiento jurídico, el cual permite la reforma total de la Constitución. Pero ello no puede interpretarse como la constitucionalización de la propia autodestrucción del texto constitucional, hecho sin precedentes en el constitucionalismo contemporáneo, sino que hay que efectuar una interpretación favorable a la existencia de límites materiales implícitos. Una vez aceptada su existencia, podrá discutirse cuales son estos principios constitucio- 
nales, pero a este debate escapa necesariamente el más importante de todos ellos: el principio democrático, que tiene toda una serie de manifestaciones concretas o subprincipios.

Es decir, la ciudadanía, y con más intensidad si se quiere, todos los poderes públicos, deben vivir en Constitución, pues hay que hacer efectivo el principio de supremacía constitucional, que implica que la Constitución vincula, aunque con distinta intensidad, a todas las personas y entes (art. 9.1. CE), incluyendo a los poderes privados, los cuales, por otra parte, justifican su existencia y actividad bajo el manto constitucional. Ello supone que no valen los silencios, sino que son necesarias las actuaciones positivas; que la educación en valores constitucionales y democráticos (art. 27.2. CE) es una exigencia constitucional; que es cierto que las crisis económicas provocan un aumento de las desigualdades sociales; que el llamado «rearme axiológico» de la sociedad civil no puede ser teledirigido; que no podemos permitirnos la actual desafección ciudadana hacia la clase política; que la corrupción no puede ser nuestro sistema de gobierno; que la publicidad y la transparencia son consustanciales al sistema democrático; que la opinión pública no es igual que la opinión publicada, etc.... Y todo ello no puede ser ajeno a los poderes privados. La pluralidad es la savia nueva para el rearme, y la denominada «globalización» puede ser una trampa del pensamiento único. De lo contrario, se producirán toda una serie de consecuencias que conducirán, inevitablemente, a una crisis de legitimidad del propio sistema.

\section{LA FALACIA DE LA ACTUAL CRISIS ECONÓMICA}

Anteriormente nos hemos referido a las tres crisis económicas del capitalismo contemporáneo: la de 1929, la de 1973 y la del 2008. La primera es una crisis propia del sistema capitalista. La segunda, que también tiene esta consideración, pone en tela de juicio los planteamientos del Estado social. Y la tercera es una crisis de legitimidad del sistema. Aunque puedan apreciarse elementos comunes a todas ellas, lo cierto es que la del 2008 presenta diferencias sustanciales en relación con las dos anteriores. En efecto, ahora resulta difícil poder afirmar que nos encontramos ante una nueva manifestación de una crisis cíclica del sistema capitalista, inherente a sus propias contradicciones internas. En los momentos actuales, además de ser una crisis económica con características propias es, también y principalmente, una crisis de legitimidad del propio sistema, pues presenta elementos axiológicos e institucionales de un sistema concreto de producción que hasta ahora parecía no tener alternativa posible. Y ello, porque los poderes públicos se han mostrado incapaces de realizar un idóneo control sobre 
los poderes económicos, mediante la incorporación de los mismos al propio proceso constitucional, y de adecuar el funcionamiento del sistema democrático a las nuevas circunstancias. Es decir, se mantiene formalmente la democracia política, aunque sea a costa de una paulatina desaparición del pluralismo político y social, sin que la llamada democracia económica se atisbe por ningún lado. Ante ello, los poderes económicos no pueden actuar sin límite alguno, pues el ejercicio del derecho de propiedad, que ni siquiera es un derecho fundamental, no es absoluto. Y si bien es cierto que su posición no es la misma que la de los poderes públicos, también lo es que el principio democrático no es ajeno a su existencia y funcionamiento. Por ello, la idea de control sobre aquellos, control de distinta naturaleza si se quiere, no es sino una consecuencia más del proceso de constitucionalización de lo privado que estamos defendiendo.

Posiblemente sea lícito afirmar que la salida de la actual crisis económica se producirá tarde o temprano, aunque muchos sectores sociales vean disminuido su poder adquisitivo y, en suma, las relaciones entre el capital y el trabajo se vean seriamente afectadas, pero más complicado es defender que la salida de la crisis económica conllevará necesariamente la superación de la actual crisis institucional y de legitimidad en que nos encontramos. La utilización impune de aquella para profundizar en estas últimas puede conducirnos a una situación de permanente crisis institucional y de legitimidad, aunque hayamos superado, con mayor o menor acierto, la crisis económica.

Si ello es así, hay que proclamar que la actual crisis económica esta incidiendo directamente en la problemática actual del Derecho constitucional, no sólo en nuestro sistema político interno, sino también a nivel europeo, poniendo de manifiesto las incapacidades del mismo para proporcionar soluciones alternativas a las oficialmente planteadas, que existen, y que implican o deben implicar una sustancial transformación del constitucionalismo contemporáneo. La cuestión puede llegar a adquirir dimensiones terribles, pues parece que el Derecho ha dejado de ser capaz de solucionar los conflictos sociales y políticos existentes, haciendo una dejación de sus funciones y entregando a otras instancias (individuales y colectivas) la respuesta a los mismos. Y no se trata tan sólo de una pérdida de la calidad democrática, sino de una involución de la propia democracia. La negativa a que los titulares del poder constituyente se pronuncien (como sucedió en el caso del pretendido referéndum griego y en la negativa a un referéndum en la reforma constitucional española del 2011), o la imposición del cambio de gobernantes, ajenos a los procesos electorales o parlamentarios, o de reformas constitucionales, provenientes de decisiones personales o por exigencias de los mercados, que se atribuyen de este modo la titularidad del poder constituyente de cada país, son claros ejemplos de todo ello. Para evitar estas circuns- 
tancias, el propio sistema democrático debe cumplir también sus obligaciones, no pudiendo adoptar una actitud conformista con su «calidad» democrática, reducida a procesos electorales periódicos. Debe proceder, pues, a una mayor integración de las nuevas realidades sociales, de los nuevos grupos emergentes, intentando que las demandas que estos plantean sean consideradas por el propio sistema y que no queden al margen del mismo, pues, de lo contrario, estas se dirigirán a otros sectores o poderes, los cuales, al propiciar su satisfacción, podrían llegar a convertirse en elementos alternativos y sustitutivos de los poderes democráticos, quienes, por su propia incapacidad, pierden entonces la legitimidad de que han sido investidos.

Como es sabido, el Derecho constitucional liberal, por su propio sustrato ideológico, nunca contempló la posibilidad de regular las crisis económicas, las emergencias, pues éstas eran un imposible ideológico. Por ello, inicialmente consideró incluso innecesario el establecimiento de un sistema de garantías de los elementos estructurales del sistema, tal y como sucedía con los derechos y libertades, razón por la cual los primeros textos constitucionales del liberalismo carecen de cualquier regulación normativa al respecto. Y es que el tríptico revolucionario liberal (Libertad, Igualdad y Fraternidad), base del sistema de derechos y libertades, no podía verse afectado por alteraciones políticas o económicas del sistema, resultando innecesario un desarrollo normativo y articulado del mismo. No resulta fácil saber si éste planteamiento ingenuo y platónico fue consciente o no. Pero lo cierto es que existió y adquirió la condición de credo político, de dogma de $\mathrm{fe}^{20}$. Ello condujo, aunque pueda resultar una paradoja, más a una intensa «publicación» de lo privado que a una «privatización» de lo público, pues las grandes corporaciones empezaron a desenvolverse como Estados propios y singulares, dotándose de sus propias normas, reclamando «su» seguridad jurídica en su propio beneficio, configurando a los consumidores como «sus» propios súbditos, creando «su» propia burocracia, etc...

Por otro lado, hay que tener en cuenta que la necesidad de los estados de emergencia vino determinada, por ataques directos al propio sistema liberal, cuya legitimidad era cuestionada por los movimientos antisistema. Por ello, el Estado liberal carecía de instrumentos normativos adecuados cuando aparecen las primeras crisis económicas del sistema capitalista, debiendo acudir a ese Derecho común y superior que es el Derecho constitucional. Y ello, porque el Derecho principial es el que mejor puede garantizar la doble función de los

20 Sobre el origen histórico de los derechos y los momentos revolucionarios, constituyen obras clave las de Maurizio FIORAVANTI, Constitución. De la Antigïedad a nuestros días, Madrid, 2001; y Los derechos fundamentales. Apuntes de historia de las Constituciones, Madrid, 2000. 
estados de emergencia: por un lado, defender las conquistas revolucionarias consolidadas por la burguesía; por otro, impedir, salvo caso extremo, la incorporación de otros planteamientos revolucionarios, de otras demandas requeridas por las nuevas clases sociales emergentes. En consecuencia, la idea de seguridad acabará por imponerse sobre la idea de libertad, siendo la seguridad nacional, especialmente la debida a causas estrictamente económicas, el bien constitucional digno de protección por antonomasia.

Frente al anterior planteamiento, sin embargo, las crisis económicas posteriores rebasan ese ámbito nacional y se centran en los elementos estructurales del sistema. Así, la crisis de 1973 va a poner de manifiesto la incapacidad del sistema para mantener los postulados del Estado social, el cual apenas había estado vigente en las democracias occidentales, las cuales, por otro lado, carecían de alternativas históricas viables.

Así, en principio, la actual crisis económica no es generada por sujetos alternativos al sistema, sino por sujetos situados dentro de aquél, pertenecientes a su propia esencia estructural. Estos sujetos activos son los grandes bancos, empresas, agencias, normalmente de carácter multinacional, que parecen luchar contra unos sujetos pasivos (la ciudadanía, el propio Estado), que también forman parte del sistema. Es decir, parece producirse una inversión del papel de los sujetos, tanto activos como pasivos, de las crisis económicas anteriores. Esta inversión se produce porque los grandes poderes privados se han alejado de los planteamientos constitucionalistas, sustrayéndose a sus propios principios informadores. $\mathrm{O}$ también porque nunca han vivido en ellos, consecuencia directa de que en épocas históricas pasadas, el mundo privado permanecía ajeno, aunque controlándolo, al espacio jurídico-político. Ahora es imposible que ello continúe siendo así. Ya no hay dicotomía entre ambos espacios. De ahí que una de sus pretensiones principales, su pretensión fundamental, sea la de invadir y apropiarse también de los espacios públicos, mientras los ahora llamados «sujetos pasivos», especialmente los poderes públicos, no han sido capaces de sujetarlos dentro de las premisas del contractualismo democrático, pues se han acostumbrado a «vivir» al margen del marco constitucional.

Es decir, se ha convertido en norma lo que por la propia evolución del constitucionalismo tenía que haber sido la excepción. El Estado liberal justificaba que los espacios privados permaneciesen al margen, pues no formaban parte de las características del propio Estado, de sus elementos configuradores. Ello ya no es posible cuando se instaura el Estado social y el principio democrático empieza a ser la fuente legitimadora del mismo. Ya no se puede hablar de una separación entre espacios públicos y privados y, mucho menos, de la prevalencia de estos sobre aquellos. Pero lo cierto es que el afán ilimitado de obtener más 
plusvalías por parte de unos, no ha recibido una respuesta adecuada por parte de otros. Y el planteamiento de la crisis, además de representar una falacia evidente, no deja de ser la expresión más contradictoria de los actuales esquemas del sistema capitalista, pero que contiene una característica novedosa: dicho planteamiento, dicha falacia, resulta difícilmente contestable. Ese es el problema fundamental en el que actualmente nos encontramos.

Las crisis económicas de determinados sujetos activos (bancos, empresas, multinacionales), debidos en buena medida a problemas de gestión interna y de afán desmesurado y sin control por la obtención de plusvalías económicas y políticas cada vez más elevadas, repercuten directamente en una serie de sujetos pasivos (ciudadanía, poderes públicos), los cuales, además de haber sido la fuente de obtención de dichas plusvalías adicionales y excesivas, deben proceder ahora a sufragar, a pagar, dicha crisis de los sujetos activos. De lo contrario la quiebra de estos, a la cual han sido total o parcialmente ajenos, corre el riesgo de convertirse en una quiebra global del sistema, que será aprovechada por otros sujetos activos, inicialmente no afectados por aquella, para proceder a una ocupación total de aquél, alterando su esencia y estableciendo unas nuevas reglas de funcionamiento para el mismo. Es decir, los enemigos del sistema no se encuentran fuera del mismo, sino que están plenamente insertos en aquél, ocupando incluso posiciones preeminentes. Y además, lo cual no deja de ser una paradoja alarmante, no se ven vinculados por los principios que rigen la actuación de los espacios públicos.

Este planteamiento afecta de distinta forma al sistema democrático. No se pretende un desmantelamiento global y radical del mismo, realizado en un sólo acto. Lo que se trata es de destruir las estructuras políticas más débiles del sistema, culpándolas de la propia crisis económica y haciéndolas desaparecer para solucionar esta. La deconstrucción parcial de los servicios públicos básicos y la desaparición de un buen número de estructuras político-administrativas se convierten en elementos propicios de la crisis. Con ello, además, se fomenta la invasión por parte de los poderes privados de toda una serie de espacios públicos, señalando que estos habían sido incapaces de llevar a cabo sus propias funciones y competencias y, en consecuencia, alimentando la existencia de la crisis. La reducción del gasto público mediante la disminución de los servicios sociales prestados, el aumento de los ingresos a costa de los que menos tienen, la desaparición de importantes estructuras administrativas, la reconversión y recentralizacion del modelo autonómico, etc... se convierten en victimas propiciatorias. Las desigualdades se acrecientan, se agigantan, y los conflictos sociales, a veces incluso violentos, comienzan a expresarse. Las teorías del Estado "paternalista» emergen de nuevo, pareciendo producirse una vuelta, no sólo a planteamientos 
estrictamente liberales propios del Estado «mínimo», sino incluso medievales: el ora et labora parece adquirir un nuevo significado.

Es decir, la ciudadanía, como sujeto pasivo, se ve obligada a renunciar a una buena parte de sus derechos y libertades, especialmente los de carácter social (sanidad, educación, vivienda, dependencia, servicios sociales), pasando a ingresar en colectivos de pobreza o de paro endémico e integrarse, a la larga, en movimientos por la regeneración democrática ${ }^{21}$, o incluso antisistema, que pueden dar lugar a conflictos sociales violentos. La irreversibilidad de las conquistas sociales alcanzadas se convierte en papel mojado, y el Estado social en una pura quimera, afectando a sectores integrados por personas que habían proporcionado una legitimidad social al sistema, las clases medias, las cuales tienen una cierta tendencia a desaparecer; y provocando que el principio revolucionario de la Igualdad, insuficientemente o apenas desarrollado por el Estado social, se convierta en un auténtico residuo histórico. Ello, además, puede contribuir a una mayor diferenciación, y por consiguiente enfrentamiento, entre las clases sociales, que a la postre puede conducir a una fractura social importante, pues siempre existen sectores de la ciudadanía, aquellos que han provocado directa o indirectamente la crisis, que se benefician de la misma, consiguiendo las plusvalías económicas anheladas.

Esta quiebra del principio de igualdad afecta a todos los servicios públicos, a todas las políticas públicas que hasta ahora realizaban los poderes públicos, pretendiéndose una privatización de las mismas, bien directamente, bien a través de conceptos como la externalizacion de la gestión, que no son sino nuevas fuentes de ingresos para aquellos poderes privados ${ }^{22}$ que habían producido la crisis, ahora ya no solo por razones económicas de sus propias organizaciones sino, principalmente, con la finalidad de cambiar y alterar los elementos estructurales del sistema. Incluso la consagración teórica de la igualdad real y efectiva de mujeres y hombres, una de las conquistas claves del Estado social todavía en lento proceso de configuración, se ve profundamente alterada, volviendo a ser las mujeres quienes más padecen la crisis, bien directa o indirectamente, en lo que corre el riesgo de representar una notoria involución de los progresos alcanzados.

Todo ello implica poner en evidencia que lo privado puede invadir todos los espacios públicos, alegando, pero no siempre demostrando, que el mismo es mucho más eficaz en la prestación de los servicios públicos. Es decir, se acude a

21 Cfr. M.A. PRESNO LINERA, «El 15M y la democracia real», El Cronista del Estado Social y Democrático de Derecho, n. ${ }^{\circ}$ 25, 2012, pp. 38 ss.; o E. GUILLEN LÓPEZ, «El 15-M desde la óptica del socialismo democrático», El Cronista del Estado Social y Democrático de Derecho, n. ${ }^{\circ} 30$, 2012, pp. 30-ss.

22 G. LOMBARDI, Potere privato e diritti fondamentali, Torino, 1970. 
la falacia, no de negar la necesidad de los mismos, sino de atribuir su prestación a otros titulares, a los poderes privados, por entender que están más capacitados para ello. Con ello, con la atribución a los poderes privados de la gestión de lo público, lo que realmente se consigue es proporcionar a aquellos nuevos ámbitos de actuación nuevos espacios con los que aumentar sus plusvalías. Y además, esto se configura como un paso intermedio, pues el resultado final parece estar planificado: la sustitución total de lo público, que se convertiría en un elemento absolutamente residual, por lo privado. Los parámetros económicos — la eficacia y la eficiencia no contrastada - se imponen a los principios constitucionales, los cuales simplemente desaparecen. Y el principio democrático es absolutamente vaciado de contenido.

Los otros sujetos pasivos, los poderes públicos, cuya pasividad es producto de su falta de liderazgo, también resultan directamente afectados. Al ser aquellos los que deben proporcionar, a través de decisiones políticas contrarias al Estado Social consolidado, los ingresos a los sujetos activos causantes directos de la crisis, necesitan, no sólo imponer esas decisiones a la ciudadanía, sino transformarse radicalmente, aceptando decisiones tomadas por órganos o personas externas al propio Estado. La reducción de la dimensión del Estado corre el riesgo de llevarse a cabo hasta límites insospechados, dentro de un proceso de privatización radical que podría implicar una desconstitucionalizacion total de lo privado. Si históricamente hay ejemplos de poderes privados que crean estructuras estatales, aceptando incluso la asunción de algunos principios y valores constitucionales, como puede ser la Liga Hanseática o determinadas colonias norteamericanas, por ser favorecedoras de sus propios interés económicos, ahora se va a producir un proceso inverso: se desmantelan las estructuras públicas estatales, reduciéndolas a su mínima expresión, con el pretexto de un ahorro sustancial en el gasto público, pero con la finalidad de proceder a su sustitución por determinados poderes privados, pues lo que da soporte a la «política», a lo público, es decir los intereses comunes, necesitan seguir siendo mantenidos en tanto constituyen, simple y llanamente, una necesidad humana. Es decir, se provoca una quiebra del Estado y luego se procede a la compra del mismo a bajo precio. De hecho, hoy día es posible incluso cuantificar el coste, aunque sea en grandes magnitudes sujetas a errores, del rescate económico de Estados como Grecia, Irlanda, Portugal, España e Italia. $Y$ es posible también encontrar poderes privados que dispongan de los medios materiales necesarios, del dinero suficiente, para proceder a la compra de los mismos. De este modo, los Estados se incorporan al sector privado y pasan a formar parte del patrimonio de los poderes que dominan aquél. Y con los Estados, toda la ciudadanía. 
Los intereses de los poderes privados, sin control alguno por parte de los poderes públicos, como era su obligación política y jurídica, y desprovistos ya de su «apariencia constitucionalista», conducen a una sustitución que altera los esquemas del Estado social, afectando a su propia legitimidad. Aunque la historia posiblemente no se repite, sin embargo sus enseñanzas parecen olvidarse, pues el principio democrático, que era el elemento legitimador del sistema, desaparece materialmente, y sólo la forma, y ello no siempre, se mantiene. Por su parte, la libertad y la igualdad se sacrifican en aras de una pretendida seguridad económica. Y finalmente la fraternidad (la solidaridad, en nuestra terminología), que debería haber sido una opción por una intervención pública a favor de los más débiles, es simplemente una utopía.

Las anteriores consideraciones ponen de manifiesto que la actual crisis económica es una auténtica falacia. La falacia es un razonamiento incorrecto que aparenta ser correcto. Pero que un razonamiento sea falaz no implica que su conclusión sea falsa, pues lo que lo hace falaz es la incorrección del razonamiento en sí. Por ello, todo razonamiento falaz es inválido, pues sus premisas no garantizan la veracidad de su conclusión. Sin embargo, esto no nos impide observar que en ocasiones aquellas pueden ser muy sutiles y persuasivas, pues la conclusión puede llegar a ser verdadera de manera casual.

Esto es, precisamente, lo que ocurre con la actual crisis económica. Los sujetos provocadores o propiciadores de la crisis son los grandes beneficiarios, pues logran que los poderes públicos obliguen a los sujetos pasivos a sufragar la misma, produciendo al propio tiempo una privatización «mercantilizada» - y no constitucionalizada, como debería ser, llegado el caso en que se considere que la privatización de lo público está justificada-, la cual incide de forma notoria en la desaparición de sus coadyuvantes (los poderes públicos) y, lo que es peor, en una mutación del sistema que, a la postre, les resultará más favorable para sus intereses. Y ello parece tener lugar sin ningún tipo de coste político o empresarial, sin ningún tipo de control y, prácticamente, sin ninguna responsabilidad. Frente a ello, los poderes públicos entran en la dinámica de limitarse, sin más, a aceptar sus pretensiones, sin oponer apenas resistencia alguna. Y es que parece que se corre el riesgo de que su supervivencia, aunque sea meramente formal, les importe más que el mantenimiento de los propios principios constitucionales.

Esta última situación parece llevarnos a una conclusión en absoluto deseada: ¿Cómo van a poder los poderes públicos constitucionalizar a los poderes privados si ni siquiera ellos mismos defienden los propios principios constitucionales? $\mathrm{Si}$ ello es así, en buena lógica constitucional, sólo restaría una solución: llamar al poder constituyente para que sea éste el que decida la incorporación o no de nuevas decisiones políticas fundamentales. Y naturalmente exigir responsabili- 
dades, del tipo que sean, a todos aquellos poderes públicos que no han sabido o querido cumplir la función constitucionalmente encomendada.

Aunque las diferencias existen, es como si los delincuentes, una vez cometido, de forma dolosa o culposa, el correspondiente delito, es decir, una vez provocada la crisis económica, obligasen a los poderes públicos afectados —en éste caso ejemplificativo, a los órganos judiciales-, a meter en la cárcel —a pagar la crisis- a sujetos inocentes y a declararles culpables con la correspondiente pena. Situación esta que alteraría todo el sistema penitenciario — sistema democrático- - pues los inocentes cumplen la pena, los culpables continúan delinquiendo y el sistema se transforma o desaparece, atribuyendo a los culpables la potestad jurisdiccional de determinar quién es inocente y quién es culpable.

Parece, pues, llegado el momento de empezar al menos a valorar que estos sujetos activos, que con sus decisiones llegan a producir la quiebra de Estados enteros, sean objeto de la correspondiente sanción penal ante organismos internacionales (Corte Penal Internacional) como auténticos responsables de crímenes económicos de lesa humanidad. Todo ello teniendo en cuenta que el Derecho constitucional, si es que ello resulta necesario, debe estar llamado a proporcionar al Derecho penal los principios y elementos estructurales necesarios para proceder a la tipificación de nuevos delitos.

Aún hay tiempo, y de hecho sobre esta dinámica se trabaja constantemente, para que los poderes públicos estatales sean capaces de constitucionalizar un espacio público internacional, que no se deje controlar por los poderes privados. No debemos olvidar los elementos de debilidad de las actuales organizaciones internacionales, carentes, si se quiere con excepciones, de un auténtico poder decisorio, el cual continúa radicado en los propios Estados ${ }^{23}$. Es decir, si los ataques a estos provienen fundamentalmente de aquellos, pues los poderes privados internos estatales o no existen o son simples correas de transmisión de los poderes privados internacionales, la respuesta no pueden producirse exclusivamente dentro del marco estatal. Se trata de seguir trabajando para generar procedimientos de responsabilidad internacional que actúen de freno frente a los poderes privados internacionales. A los Estados les puede corresponder otra función, como es la acusatoria, pero el juicio, la exigencia de responsabilidad ha de residenciarse en los poderes públicos supranacionales. Con ello se trata de reivindicar la eficacia horizontal del espacio internacional constitucional, evitando que los poderes privados ocupen todo el espacio público.

23 La llamada «movilización de la vergüenza», en palabras del profesor Pastor Ridruejo, parece seguir siendo la principal arma del espacio jurídico internacional. Cfr. L. PASTOR RIDRUEJO, El derecho Internacional: normas, hechos y valores, Madrid, 2005. 


\section{LA GLOBALIZACIÓN Y EL DERECHO CONSTITUCIONAL}

A estas alturas no añadimos nada nuevo si afirmamos que la llamada sociedad de la información y el proceso de globalización en que estamos inmersos han transformado radicalmente las relaciones de producción. Ahora bien, mientras la existencia de un mundo globalizado ha obtenido respuestas desde un punto de vista económico, con la apertura ilimitada de los mercados, y de modo manifiesto desde un punto de vista tecnológico, sin embargo las respuestas son insuficientes desde un punto de vista normativo-constitucional. Es decir, los poderes privados parecen haberse adaptado mucho mejor que los poderes públicos a éste nuevo escenario, que les resulta más favorecedor para sus intereses. $\mathrm{O}$, lo que es más cierto, aquellos han impedido que estos se adaptaran a las nuevas realidades, pues, de éste modo, el control sobre los mismos desaparece ${ }^{24}$. Con ello, lo que se ha logrado es que los poderes económicos, los poderes privados, pugnen por imponerse - $\mathrm{y}$ de hecho lo hagan en muchas ocasiones - a los poderes públicos, a los poderes políticos, utilizando una serie de reglas, procedimientos y pautas de conducta que escapan al control por parte del Derecho. Por ello, resulta cada vez más necesario proceder a una «deconstrucción» de todas aquellas categorías dogmáticas que únicamente han servido para explicar la evolución y el significado del Estado-nación. El nuevo espacio impone, necesariamente, nuevos conceptos jurídicos.

No se trata, como así lo hacen algunos planteamientos ideológicos, de fomentar un antagonismo entre los poderes públicos y los poderes privados, en base a que los intereses de unos y de otros son también antagonicos y opuestos. Aunque ello pueda ser cierto en determinadas ocasiones, la misión del Derecho constitucional como Derecho común y principial es la de cohonestar dichos intereses dentro de un mismo espacio, a cuya formación concurren ambos tipos de poderes, los públicos y los privados. Esta es la finalidad esencial que persigue la llamada constitucionalización de los espacios privados, pues las decisiones políticas fundamentales, la reserva de Constitución, debe ser comúnmente aceptada, ya que el constitucionalismo contemporáneo supuso, de hecho, el compromiso por aceptar unos mismos principios y valores constitucionales; y nuestros intereses, aunque no coincidan totalmente, pueden defenderse en un mismo espacio.

24 Sobre el fenómeno de la globalización, cfr., entre otros, F. FUKUYAMA, El fin de la historia y el último hombre, Madrid, 1992; A. GIDDENS, Un mundo desbocado. Los efectos de la globalización en nuestros días, Madrid, 2000; S.P. HUMTINGTON, El choque de las civilizaciones y la configuración del orden mundial, Madrid, 1997; J. HABERMAS, La inclusión del otro, Barcelona, 1999; D. HELD, Modelos de democracia, Madrid, 2001; S. CASSESE, La globalización jurídica, Madrid, 2006; A. PIZZORUSSO, La produzione normativa in tempi di globalizzazione, Turin 2008. 
No cabe negar, no obstante, que en determinados espacios geográficos limitados - por ejemplo la Unión Europea o el Consejo de Europa- o en aspectos sectoriales concretos - la Corte Penal Internacional, cuya existencia no ha sido ratificada por los Estados más poblados e importantes, razón por la cual en más de diez años únicamente ha puesto una sentencia condenatoria-, se ha intentado dar una respuesta normativa global, aunque esta tenga un carácter parcial, y aunque esta corra igualmente el riesgo de verse arrastrada por la relativización interesada de los principios constitucionales. Adviértase que la incapacidad de los poderes públicos de proporcionar una respuesta global viene condicionada por la negativa de los poderes privados a permitir dicha respuesta, con la amenaza de una inestabilidad económica permanente y, en último caso, con la propia desaparición de aquellos. Esta postura implica que aún estamos lejos de una integración de todos los intereses en liza, cuestión esta que se nos antoja como una de las prioridades fundamentales del proceso de constitucionalización de lo privado. El espacio supranacional, quizás por la confluencia de intereses diversos, ofrece no obstante ciertas garantías - mayores o con mayor idoneidad si se quiere- - para que las prioridades ligadas a los valores del constitucionalismo contemporáneo no queden en segundo plano. Pero ello no debe suponer el abandono del marco estatal como punto de referencia fundamental.

En el fondo, todo ello ha conducido a una enorme complejidad de las sociedades democráticas avanzadas, cada vez mas interdependientes entre sí, lo cual parece exigir la adopción de nuevas formas políticas superadoras del viejo Estado nacional, donde éste continúe siendo el eje del sistema, pero que se traduzcan en una nueva estructuración de la sociedad globalizada que continúe ampliando y perfeccionando el constitucionalismo del espacio internacional.

Si a las anteriores dificultades añadimos que la posible respuesta por parte de los poderes públicos no puede o no quiere desprenderse de los viejos residuos históricos de las democracias occidentales, de las clásicas categorías dogmáticas, el panorama puede resultar desolador. La vuelta a los planteamientos del Estado mínimo, que ya se produjeron desde determinados sectores políticos en la crisis de 1973, parece tener allanado el camino. El principio monárquico se impone de nuevo sobre el principio democrático y la libertad, la igualdad y la fraternidad (solidaridad) son sacrificadas en aras de una pretendida bondad de la seguridad económica, fundamentada en una fuerte privatización escasamente constitucionalizada, la cual por sí misma proporcionará nuevas seguridades.

Llegados a este punto quizás debamos señalar que de la situación actual únicamente es posible salir con un rearme axiológico, institucional y normativo por parte de los poderes públicos, los cuales están obligados a evitar la muerte del principio democrático y a mantener un adecuado equilibrio entre la libertad y la 
seguridad. Las respuestas exigen nuevas categorías dogmáticas, y una revisión en profundidad de las existentes. Y esta tarea corresponde, primariamente, al Derecho constitucional, pues éste ha sido, y continúa siendo, el derecho de la Libertad y de la Igualdad, debiendo transformarse, sin perder esta condición, en un Derecho de la Solidaridad, para proporcionar de este modo respuestas globales y omnicomprensivas. El Derecho constitucional, el llamado nuevo neoconstitucionalismo, ha de proporcionar a las diferentes disciplinas jurídicas — derecho administrativo, penal, pero también al civil, al mercantil...- las herramientas teóricas suficientes para poder completar, de forma sectorial, la salida de la crisis. De éste modo todo el ordenamiento jurídico, además de proporcionar una respuesta normativa al actual proceso de globalización, se convertirá en un elemento transformador de la realidad social, función esta que sólo ha cumplido, si es que lo ha hecho, en contados momentos históricos o de forma parcial.

La idea inicial de la que hay que partir es precisamente la contraria a la que ha fraguado la actual crisis económica y del sistema. Frente al mero recurso a la privatización de lo público se impone una constitucionalización de los espacios privados como una decisión política fundamental que ha de llevar a cabo la comunidad política y, en consecuencia lógica, incluirla en su norma fundamental y en su desarrollo constitucional. Y no se trata de rechazar sin más, y sobre todo sin fundamentación alguna, las técnicas propias de la gestión privada, sino de hacer que continúen perviviendo los principios y valores constitucionales, a los cual deben estar supeditadas aquellas. La llamada nueva gestión pública o la teoría del Management, tan de moda en épocas pasadas, no es sino una manifestación de este proceso. Es decir, al igual que no hay categorías dogmáticas exclusivas de lo público y de lo privado, sino categorías comunes para ambos, también las técnicas utilizadas deben tener un carácter común, con independencia de cual haya sido su origen y primitivo significado. Lo mismo, por lo demás, puede decirse de la teoría de la gobernanza. De ahí la reivindicación constante de la importancia del Derecho constitucional en la salida de la crisis y en el otorgamiento de una nueva legitimidad democrática al sistema. Así pues, para su articulación habría de pensarse en los siguientes parámetros que apenas esbozamos.

\section{A) Una nueva teoría del Estado}

El Estado, como forma histórica del poder político, ha experimentado cambios notables desde la aparición de los primeros Estados nacionales. Hoy día las características estructurales — soberanía, territorio, ejércitos permanentes, moneda, orden jurídico propio, etc....- han dejado de existir o se han transformado 
radicalmente, y las actuales estructuras políticas tan solo mantienen el nombre, pero no sus elementos clásicos. La cesión del ejercicio de soberanía a organizaciones supranacionales —ONU, OTAN, UE-, y su adecuación para una gestión eficaz de las actuales políticas públicas en determinados sectores - lucha contra el terrorismo, inmigración, etc....- cuestionan la viabilidad actual del Estado, tal y como lo demuestra su carencia de medios necesarios para resolver la actual crisis económica, trasladando la solución de la misma a organismos supranacionales o a poderes privados.

Frente a la certeza de estos planteamientos, a nuestro juicio hay que reivindicar todavía hoy día la viabilidad de las estructuras estatales, aunque con un contenido y significado diferentes. En efecto, el Estado continúa siendo un centro de imputación jurídica importante, es la base y el eje sustancial de las actuales organizaciones internacionales, y sirve de marco de referencia a muchas políticas públicas. Además, los poderes públicos estatales se encuentran más legitimados y capacitados que las estructuras intergubernamentales para actuar como contrapeso, y en suma ejercer las funciones de control y sanción, de los excesos y pretensiones de los nuevos poderes privados. Por otro lado, los intentos de hacer desaparecer el Estado, el único que puede garantizar hoy día el mínimo vital constitucional, la antigua procura existencial si se quiere ${ }^{25}$, o la privatización de los mismos, se configuran más bien como un deseo de los poderes privados, pues la debilidad de las actuales organizaciones supranacionales es más favorable a sus pretensiones.

No debemos olvidar, en suma, que el Estado parece ser el mejor marco adecuado para hacer desaparecer las actuales desigualdades existentes. Por el contrario, la globalización precisamente lo que hace es aumentarlas pues, al fin y al cabo, lo que realmente se produce es una globalización de la pobreza y de la desigualdad y un dominio del más fuerte sobre el más débil.

Este proceso de redimensionamiento del aparato estatal, con la reducción del gasto público y la desaparición de determinadas estructuras estatales, puede conducir a consecuencias funestas. Frente a ello, a nuestro juicio, hay que evitar la pérdida de la centralidad del Estado y su sustitución por otras centralidades radicadas en organismos supranacionales o en los propios poderes privados. El orden internacional no es nada sin los Estados, pues estos continúan teniendo la última palabra; y la tutela de estos por los organismos internacionales, o por otros Estados económicamente mas poderosos, no es sino un intento de desaparición de los mismos en aras de la satisfacción de determinados intereses espureos, perfec-

25 W. FORSTOFF, Concepto y esencia del Estado social, Madrid, 1986; y El estado de la sociedad, Madrid, 1987. 
tamente compatibles con los intereses de los grandes poderes privados. Pero ello no supone, ni mucho menos, una defensa del estatalismo a ultranza, con la existencia de todo un proceso desbocado de regulación normativa ${ }^{26}$. Al contrario, y naturalmente rechazando los planteamientos del Estado mínimo, el marco estatal debe hacer realidad las grandes decisiones políticas fundamentales que también desde el orden constitucional internacional se contribuye a elaborar, a modo de vigilante diverso — más allá del interés particular de cada Estado_-, permitiendo y fomentando que otros actores, en este caso los poderes privados, participen en su ejecución, lo cual exige una previa aceptación y asunción de dichas decisiones básicas como propias. En suma, las decisiones políticas fundamentales deben ser adoptadas por la comunidad política que vive bajo la Constitución.

\section{B) Un nuevo concepto de representación}

El Estado contemporáneo es un Estado sustancialmente representativo, con arreglo a una serie de principios y técnicas que no se han transformado en sus líneas básicas, desde los planteamientos revolucionarios liberales. Este carácter, tras las grandes discusiones teóricas de los clásicos decimonónicos, pudo servir para realizar todo un proceso de integración de fuerzas políticas antisistema en las pasadas décadas, contribuyendo de este modo a la legitimación del propio sistema. Pero hoy día resulta absolutamente insuficiente, no bastando con la alteración de unas u otras técnicas representativas más legitimadoras — simples cambios en los sistemas electorales, aún sin negar su importancia-, sino que se impone un cambio del modelo de la representación política y, en consecuencia, de la legitimidad del sistema mismo.

Si bien no se trata de una vuelta al mandato imperativo, es obvio que el mandato representativo, en su configuración actual, parece no ser ya suficiente. La ciudadanía siente que existe una carencia comunicativa y una falta de participación cotidiana en la toma de decisiones. Y por lo mismo, aquélla no puede permanecer en una actitud pasiva, limitándose a elegir a sus representantes, lo cual paradójicamente parece aceptarse cuando el contexto socio-económico le resulta favorable y, por el contrario, emergiendo una actitud reivindicativa cuando la crisis aflora. El compromiso ha de ser, pues, recíproco, debiendo articularse una especie de nuevo contrato social que se traduzca en la potenciación de la transparencia y la rendición de cuentas basada en la idea de una información veraz, continúa y elaborada, el fomento de una ciudadanía activa e implicada de

26 E. GARCÍA DE ENTERRÍA, Justicia y seguridad en un mundo de leyes desbocadas, Madrid 1999. 
modo constante, y la articulación de un diálogo bidireccional, consciente y riguroso entre ambos actores.

En efecto, dados los actuales momentos, la aparición de nuevos grupos críticos - y, en ocasiones, antisistema-, los cuales proclaman no sentirse representados en las estructuras políticas, debería servir para concienciar a los poderes públicos afectados de la necesidad de un cambio de modelo, pues lo que resulta ilógico es admitir que la situación derive hacia la propia existencia de fuerzas antisistema como algo normal. La integración es una característica de todos los sistemas políticos democráticos. Lo contrario, el coadyuvar a la proliferación o incluso normalización de fuerzas antisistema, no es sino fomentar una deslegitimación de aquellos.

En suma, frente a la llamada democracia representativa se impone la llamada democracia de identidad, que va más allá de la democracia deliberativa, como un nuevo sistema de integración de todos los grupos sociales. Pero ello no implica, sin más, una opción por las instituciones clásicas de democracia directa, sino la creación de nuevas formas de participación política, nuevas formas de asociación y la recuperación de la ciudadanía como sujeto activo que coadyuve a esa integración. Lo contrario supone producir nuevas desigualdades y nuevas conflictividades sociales. Se trata, efectivamente, de formalizar un nuevo contrato social entre gobernantes y gobernados, que vaya más allá de la simple elección de aquellos por estos, de tal modo que el papel de la ciudadanía mute hasta continuar participando con formulas novedosas y alternativas en las competencias desempeñadas por estos ${ }^{27}$. La legitimidad, en resumidas cuentas, no se encuentra solo en el origen de la creación de los poderes públicos, sino también, y quizás preferentemente, en el diseño de la mayor parte de la actuación de estos, dentro del margen de responsabilidad que de forma delimitada y precisa, corresponde a cada uno de los sujetos implicados.

\section{C) Una nueva teoría de la Constitución}

También la teoría de la Constitución debe ser objeto de un profundo proceso de revisión conceptual ${ }^{28}$, superando su primitiva configuración como técnica para asegurar la libertad, e incidiendo en la idea de que hay que proceder a toda

27 Vid. R. TUR AUSINA, «Participación ciudadana y evolución hacia la democracia identitaria. Análisis al hilo de la última oleada de reformas estatutarias», en la obra colectiva La solidaridad en el Estado Autonómico, Valencia, 2012.

28 Cfr., a este respecto, A. GARRORENA, Teoría de la Constitución y sistema de fuentes, Madrid, 2011; A. MARTIN DE LA VEGA, «En torno a la teoría de la Constitución y los nuevos 
una nueva constitucionalización de determinados aspectos y contenidos, haciendo viable un constitucionalismo, no sólo de la libertad, sino también de la igualdad y la solidaridad. Y todo ello porque hemos asistido, con mayor o menor intensidad, a un cierto vaciamiento normativo por parte del Estado social, renunciando así, o haciendo dejación, de uno de sus postulados fundamentales. No se trata sólo de volver de nuevo a la tensión dialéctica entre el principio democrático y el principio de supremacía constitucional, o de tratar de desentrañar quien es, si es que existe, el soberano constitucional ${ }^{29}$, sino de abordar una vez más, con una finalidad claramente revitalizadora para analizar la realidad constitucional, toda una serie de cuestiones, entre las que podrían mencionarse las siguientes:

1) El propio significado del poder constituyente, actualmente desvirtuado o descafeinado, como poder originario y creador de un orden nuevo, el cual no puede permitir verse sustituido por otros poderes, públicos y/o privados, que siempre tienen un carácter derivado y limitado. Los poderes constituidos (y podríamos ir pensando en incluir en esta expresión a los propios poderes privados, aunque no sean creados por el propio poder constituyente) no pueden asumir funciones propias del poder constituyente, y tampoco pueden efectuar una delimitación entre éste y aquellos, como a veces ha hecho nuestra jurisprudencia constitucional, pues esta función únicamente corresponde a la Constitución. Pero éste carácter del poder constituyente no puede limitarse al momento fundacional de un orden nuevo, sino que ha de tener un carácter permanente, evitando que los poderes constituidos —el poder de reforma, los tribunales, los propios poderes privados etc.... - ejerzan las competencias de aquel. Es decir, el poder constituyente no puede desaparecer una vez establecido el nuevo orden constitucional, dejando toda la labor a los poderes constituidos, incluido el poder de reforma. El poder constituyente puede y deber continuar actuando a lo largo de la vida y existencia del Estado constitucional, pues es el único que puede modificar las decisiones políticas fundamentales, el contenido de la Constitución ${ }^{30}$.

contextos del constitucionalismo», Estudios Deusto, vol. 57/2, 2009; M. CARBONELL (Comp.), Teoría de la Constitución. Ensayos escogidos, México, 2008.

29 Cfr. estas cuestiones en P. DE VEGA, «Mundialización y Derecho Constitucional. La crisis del principio democrático en el constitucionalismo actual», $R E P, \mathrm{n}^{\circ} 100,1998$, pp. 65-ss.; M. KRIELE, Introducción a la teoría del Estado: Fundamentos históricos del estado constitucional democrático, Buenos Aires, 1980. V. WOLKMANN, «El Derecho constitucional, entre pretensión normativa y realidad política», Teoría y Realidad Constitucional, n. ${ }^{\circ}$ 21, 2008.

30 Sobre el poder constituyente cfr., entre otros, E.W. BÖCKENFÖRDE, «El poder constituyente del pueblo. Un concepto límite del derecho constitucional», en Estudios sobre el Estado de Derecho, cit. 
$\mathrm{Al}$ permitirse la reforma total, como sucede en el caso español, donde no existen límites expresos materiales a la reforma constitucional, lo que sucede es que el poder de reforma se encuentra más próximo al poder constituyente que los demás poderes constituidos. Por ello urge la modificación de esta cuestión, dando entrada directa al poder constituyente al menos siempre que se intenten modificar las grandes decisiones políticas fundamentales, tal y como debiera haber ocurrido con la reforma del art. $135 \mathrm{CE}^{31}$. A nuestro juicio, la constitucionalización del espacio público es una decisión política fundamental, pero la misma no puede suponer la desaparición —o desnaturalización- de otras decisiones políticas también fundamentales, pues en caso de que ello se haga así lo que tendremos es un nuevo modelo, revolucionario o reaccionario según se mire, radicalmente distinto del anterior, con el cual no tiene nada que ver. Se habrá producido, en terminología schmittiana, un quebrantamiento del primero; y alumbrado, en todo su sentido etimológico, un orden nuevo.

2) El significado de la Constitución como norma estatal y como norma jurídica suprema. Si bien la supremacía constitucional no impide, porque lo permite la propia Constitución, la existencia de una primacía del Derecho comunitario, éste también forma parte del ordenamiento jurídico interno, igual que los textos constitucionales de los Estados miembros también se integran en el Derecho comunitario, dentro de lo que se conoce como un constitucionalismo multinivel ${ }^{32}$. Pero el principio de supremacía constitucional debe contribuir a su defensa, y no a la petrificación de su contenido. Ello al tiempo que se procede a una contestación de los diferentes sistemas jurídicos a través de técnicas y principios que permitan completar el tradicional hard law con una concepción del derecho más flexible y maleable, con el denominado soft law. Esta suprema-

31 Sobre el significado de esta reforma constitucional, cfr., por todos, E. ÁLVAREZ CONDE y C. SOUTO GALVÁN (coords.), La Constitucionalización de la estabilidad presupuestaria, Madrid, 2012. Cfr., asimismo, R. PUNSET, «Aporías de la reforma constitucional», El Cronista del Estado Social y Democrático de Derecho, n. ${ }^{\circ}$ 32, 2012; J. RUIPÉREZ ALAMILLO, «De la reforma constitucional y sus límites materiales», Teoría y Realidad Constitucional, n. ${ }^{\circ}$ 30, 2012; A. EMBID IRUJO, El Derecho de la crisis económica, Zaragoza, 2009, y La constitucionalización de la crisis económica, Madrid, 2012.

32 Sobre el constitucionalismo multinivel y algunas de sus manifestaciones, Cfr. CARROZZA, P., «El «multilevel constitutionalism y el sistema de fuentes», Revista Española de Derecho Europeo, n. ${ }^{\circ}$ 19, 2006; I. PERNICE, «Multilevel constitutionalism in the European Unión», WHIPaper 5/02-European Law Review, 2002; E. ÁLVAREZ CONDE, R. TUR AUSINA, «Los derechos en el constitucionalismo. Tipología y tutela multilevel», Teoría y Realidad Constitucional, n. ${ }^{\circ} 20,2007$; S. PICCIOTTO, «Constitutionalizing multilevel governance?», Internacional journal of constitucional law, vol. 6, n. ${ }^{\circ}$ 3-4, 2008; A. PIZZORUSSO, «La producción normativa en tiempos de globalización», $R D C E$, n. $^{\circ} 11,2009$. 
cía constitucional también implica, de otro lado, la existencia de un concepto sustancialista de Constitución, traducida en la negación de un concepto neutral de la misma, alejado de todo sistema de valores e incapaz de influir en la realidad política que debe regular. Se trata, en suma, de efectuar una clara opción por la normatividad de la Constitución, refutando todos aquellos planteamientos que proponen una desjuridificacion, pues ello supone que haya cada vez más espacios fuera del Derecho. La plena normatividad constitucional continúa siendo un problema pendiente entre nosotros, en el sentido de que todavía hay que enseñar a los poderes públicos y privados a vivir en y bajo la Constitución.

3) El contenido de la propia Constitución, con la incorporación de nuevas decisiones políticas fundamentales, de nuevos valores en suma, que supongan la ocupación del espacio que asumen los actuales poderes privados. Es decir, se trata de una nueva normativización a nivel constitucional de las relaciones privadas, pues la Constitución no es ya sólo la normativización de las relaciones entre los poderes públicos, ni entre estos y la ciudadanía. Se debe proceder, por tanto, a una nueva configuración del principio de reserva de Constitución, abandonando los antiguos planteamientos liberales, hacia los cuales parecen inclinarse los actuales poderes privados, con la finalidad de que sus propios intereses estén exentos de todo tipo de control. Reserva de Constitución que ha de tener, necesariamente, un carácter contingente, permitiendo la incorporación de posibles y nuevas decisiones políticas fundamentales adoptadas por el poder constituyente.

La Constitución no puede ser objeto de todo un proceso de expoliación conceptual y material, de contenido. Las decisiones políticas fundamentales no pueden ser alteradas como consecuencia de las sucesivas crisis económicas. Y no debemos olvidar, pese al fracaso de la Constitución europea, que no es de extrañar la existencia — formal o, en todo caso material — de Constituciones supraestatales, pues la Constitución misma no es un simple elemento estructural del Estado.

\section{D) Una radical transformación del sistema de fuentes del Derecho}

La ocupación «consentida» del espacio público por los poderes privados ha supuesto una alteración sustancial del sistema de fuentes del Derecho que es necesario rectificar cuanto antes. En efecto, cuestiones tales como la abusiva utilización de los Decretos-Leyes, el propio concepto de ley, la desaparición de los convenios colectivos como fuente del Derecho, etc., no son sino manifestaciones de esta ocupación privada del espacio público, que presenta, además, como 
tendencia general, la idea de prescindir de la forma, del procedimiento en suma, el cual es importante en todo sistema democrático. Y es que tampoco resulta ajena a éste proceso la propia incapacidad democratizadora por los poderes públicos para funcionar conforme a las reglas del principio democrático.

En realidad, estaríamos asistiendo es a un quebrantamiento de la Constitución a través de normas de rango inferior. En efecto, la utilización abusiva de los Decretos-leyes supone una alteración del significado de los derechos fundamentales de la ciudadanía en favor de pretendidas situaciones de emergencia y vías de hecho, lo cual supone un reconocimiento también del fracaso colectivo.

Si el propio concepto de Constitución debe experimentar cambios sustanciales, los mismos han de predicarse del resto de las normas que integran el ordenamiento jurídico y que se encuentran supeditadas a aquella. Las normas integrantes del ordenamiento jurídico deben completar los contenidos constitucionales. Y esta función parece que debe ser realizada con reglas más que con principios, los cuales son propios de la Norma Fundamental.

Por otro lado, con éste cambio en el sistema de fuentes del derecho se proporcionará a las demás disciplinas jurídicas los elementos teóricos suficientes para que determinadas categorías dogmáticas o determinadas técnicas normativas — desregulaciones, externalidades, etc.... — se conviertan en cauces de expresión de los intereses de los poderes privados. Por otro lado, cuestiones tales como la proliferación excesiva de leyes de intervención administrativa, el aumento desorbitado de la inejecución de sentencias relacionadas con la crisis económica, el crecimiento de la morosidad en las Administraciones Públicas..., deben cuanto antes ser puestas en cuarentena a través de un sistema de constitucionalización de las reglas económicas, pues los textos constitucionales deben regular las nuevas relaciones de poder, las cuales no pueden permanecer al margen del derecho pues, de lo contrario, difícilmente se resolverán los nuevos conflictos sociales emergentes $^{33}$.

\section{E) Un nuevo significado de los principios constitucionales y de los derechos fundamentales}

El Derecho constitucional es un Derecho principial y sus normas no pueden tener un mero carácter programático, sino que deben convertirse en normas de

33 Cfr. las diversas ponencias presentadas al XIX Congreso italo-español de Profesores de Derecho Administrativo, Madrid, octubre 2012, especialmente las de J. TORNOS MAS, «Crisis del estado del bienestar. El papel del derecho Administrativo», y J. JORDANO FRAGA, «El Derecho Administrativo de la crisis». 
aplicación directa, superando su consideración de simples parámetros de constitucionalidad. Ello proporcionará, además, un nuevo valor axiológico a las normas constitucionales, propiciando su carga valorativa y su influencia normativa sobre el resto de las normas integrantes del ordenamiento jurídico.

Además, con ello se incrementará el proceso de autoidentificación de la propia Constitución. A partir de ahora la Constitución será lo que digan los diferentes preceptos constitucionales y no lo que interpreten los poderes públicos en el ejercicio de sus funciones constitucionales, sin perjuicio de que estos sean titulares de un necesario pero limitado poder de dirección política, que puede incluso llegar a construir categorías dogmáticas innovadoras. Pero lo que no puede admitirse de ningún modo, es que la Constitución sea lo que decidan los poderes privados, pues estos no ejercen funciones constitucionales. Con ello, se contribuirá a aumentar la capacidad emancipatoria del Derecho constitucional, que se convierte, de esta forma, en un Derecho beligerante y no neutro.

Es cierto que los principios constitucionales no se encuentran totalmente positivizados en el texto constitucional, sino que deben ser inducidos de aquél, en un proceso que va mas allá de las grandes decisiones políticas constitucionalizadas. Y de hecho, estas pueden cambiarse, pues son contingentes, a través de un proceso de reforma constitucional con intervención del poder constituyente. Pero aquellos, los principios, en cambio son límites materiales inmanentes al propio proceso de reforma constitucional. Una vez admitido que el Derecho Constitucional es un Derecho principial, aunque también contenga reglas, se trata de determinar cuales son dichos principios, entendiendo por tales aquellos sin cuya existencia el ordenamiento constitucional, aunque pudiera formalmente modificarse, se encontraría desnaturalizado.

En primer lugar, haciendo un proceso de abstracción lógica, pues pueden existir principios y subprincipios, y con un carácter preferente sobre los demás, nos encontraríamos con el principio democrático, el cual informa todo el ordenamiento jurídico y la actuación de los poderes públicos y privados. En segundo lugar estaría el principio de igualdad, en sus diversas manifestaciones —igualdad formal, material, en la ley, ante la ley, etc..._-, conformador del sistema de derechos y libertades y principio de limitación de la actuación de los poderes públicos. Y, finalmente, y en un menor grado que los anteriores, el principio autonómico, como técnica racional de distribución territorial del poder político.

Los derechos fundamentales son un trasunto o una expresión de los principios constitucionales, razón por la cual resulta difícil establecer una diferenciación ontológica de los mismos, tal y como se realiza en la Carta de Niza y a diferencia del régimen jurídico, especialmente por lo que a su sistema de garantías se refie- 
re, establecido en nuestro ordenamiento constitucional ${ }^{34}$. Todos los derechos responden a una misma fundamentación teórica, siendo, por lo tanto, reprochables cuestiones tales como la infravaloración normativa o el supuesto sobrecoste de los derechos sociales y de los derechos de la cuarta generación — cómo si la democracia misma no tuviera un precio significativo-, la negación de la eficacia de los derechos frente a terceros, la compleja diferenciación — y posible devaluación para algunos derechos- entre derechos y principios rectores, etc.... Es más, la actual crisis económica debería, frente a la alternativa oficial, obligarnos a potenciar estos últimos derechos y no a prescindir de ellos. La eficacia real de un derecho no puede estar en función de las posibilidades presupuestarias existentes. En caso contrario lo que desaparece es el propio Estado democrático. Pensemos, a modo de ejemplo ficticio, que ante la inexistencia de recursos económicos para afrontar los procesos electorales, se produjese la suspensión de los mismos y la desaparición del derecho de sufragio.

\section{F) Un nuevo sistema de relaciones entre los poderes públicos y entre estos y los poderes privados}

Anteriormente apuntábamos la posible conveniencia de que los poderes privados, aún sin serlo, tuviesen en alguno modo una consideración semejante a la de los poderes constituidos. De éste modo quedarían sujetos y limitados por la acción del poder constituyente, lo cual es ideológicamente defendible. Pero ello exige un nuevo sistema de relaciones con los poderes públicos clásicos, pues estos deben permitir, mediante la utilización de las técnicas normativas adecuadas, la participación de aquellos en las funciones constitucionales de estos. Nadie descubre el Mediterráneo si afirma y sostiene que las decisiones de los poderes públicos no pueden ni deben adoptarse sin el consentimiento de los destinatarios de las mismas, ya sea la ciudadanía o los poderes privados. Y éste consentimien-

34 En efecto, la «cuestión social» no estuvo ausente de los debates sobre la elaboración de una Carta Europea de derechos. Paradójicamente, el Preámbulo de la Carta, de influencia española, alude a derechos y principios. Lo que se completa con el art. 51.1 de la Carta, pues se dispone que los primeros se respetan y los segundos se observan. Sin embargo, el hecho de que después la Carta no refleje formalmente esta subdivisión ofrece, a nuestro juicio, tintes positivos. Aunque la literalidad de cada uno de los preceptos puede llevar a uno u otro lugar, una interpretación armónica de la Carta permitiría construir derechos desde los diversos contenidos sociales, en una importante reconducción de su contenido hacia las ideas de dignidad, libertad e igualdad. Por todos, Cfr. G. ROLLA, «La Carta de los Derechos Fundamentales de la Unión Europea en una perspectiva comparada. Técnicas de codificación y cláusulas de interpretación», Revista de Derecho Constitucional Europeo, n. ${ }^{\circ}$ 11, 2009, pp. 8-ss. 
to debe obtenerse en el proceso de elaboración de la decisión en cuestión, para lo cual existen técnicas normativas conocidas, lo cual no debe impedir la posibilidad de arbitrar otras nuevas. Los últimos desarrollos normativos - fundamentalmente autonómicos_- en torno a los elementos de la democracia participativa, gobierno abierto y transparencia, son un buen ejemplo de ello, sin perjuicio de que esté todavía pendiente su implementación y consecuente evaluación.

Los diferentes poderes deben ser conscientes de su carácter derivado y limitado, debiendo ejercer sus competencias en un marco de lealtad institucional, de colaboración, de autocontrol, y de respeto a aquellos otros poderes que se encuentran más próximos al principio democrático — constituido en uno de los principios que integran la esencia de nuestro constitucionalismo-, como pudiera ser el propio Parlamento frente a otros poderes constituidos, lo que exige reivindicar su centralidad. Por tal motivo, no sólo se trata de recuperar el locus parlamentario como escenario principal de debate y diálogo, sino que además el llamado principio de deferencia hacia el legislador democrático debe evitar la reconstrucción de los mandatos normativos que únicamente le corresponden a aquel.

Si las relaciones entre los poderes públicos deben responder al principio de colaboración en el ejercicio de las competencias constitucionalmente atribuidas, lo cual es mas exigible entre nosotros dado que el nuestro es un sistema parlamentario, es decir, de colaboración de poderes, podemos encontrarnos cuando las medidas para gestionar la crisis son impuestas desde fuera y presumiblemente atentatorias a los principios constitucionales, como puede ser el principio de igualdad, con el hecho de que unos poderes públicos anulen, declarándolas inconstitucionales, las medidas adoptadas por otros. Ello es lo que ha sucedido recientemente en Portugal, al declararse inconstitucionales determinadas medidas por la vulneración del principio de igualdad. Ello puede acarrear graves consecuencias económicas que impliquen nuevos ajustes económicos, acentuando la gravedad de la crisis y proporcionando a órganos foráneos y a determinados poderes privados argumentos para una mayor privatización de lo público. Por ello, la adopción de dichas medidas exige un acuerdo previo entre los diferentes poderes públicos, y no un simple mimetismo de las decisiones adoptadas y/o exigidas por otros.

Al propio tiempo, se impone un nueva idea de control, que supere los actuales planteamientos del sistema parlamentario y se adecúe en mayor medida a los nuevos postulados del sistema representativo, evitando la discrecionalidad administrativa, revalorizando el ejercicio responsable de la oposición política, y proporcionando una entrada directa de la ciudadanía en el ejercicio de aquel. La reconstrucción de la idea de una opinión pública, diferente conceptualmente de la opinión publicada, parece imponerse con celeridad. Ello ha de conducir a un nuevo concepto de responsabilidad, política, civil y penal. Y de ambas cuestiones, el 
control y la responsabilidad, no pueden quedar exentos los poderes privados. Y es que el simple ejercicio del derecho de propiedad o de libre empresa, derecho de por sí limitado por otros derechos y bienes constitucionalmente protegidos, no puede convertirse en patente de corso para eludir los controles y la responsabilidad.

En resumidas cuentas, la constitucionalización del espacio privado significa que los poderes públicos no pueden hacer dejación de las competencias que les han sido legalmente atribuidas. Pero el ejercicio de dichas competencias ha de realizarse, eso si, dentro de un proceso de self restraint, que implica el respeto a las competencias ajenas y un deber positivo de actuar en función del interés general y en constante proceso de retroalimentación y bidireccionalidad con la ciudadanía misma y los poderes privados.

Por lo demás, estas transformaciones deben afectar también al sistema de distribución territorial del poder político, con independencia del nomen iuris que se utilice. Indudablemente, la reducción del gasto público, la desaparición de duplicidades administrativas, etc., se convierten, en tiempos de crisis económica, en bienes dignos de protección, pero sin que ello implique utilizar la crisis económica para reducir o desmantelar a las entidades subestatales — procesos de recentralizacion, devolución de competencias, disminución injustificada de parlamentarios y concejales, etc.- precisamente cuando son éstas las que prestan los servicios públicos básicos a la ciudadanía, pues ello puede llegar a suponer un ataque frontal al Estado social, que es una de las decisiones políticas fundamentales adoptadas por la comunidad. Ante una tentadora reducción del ámbito público se impone, sin embargo, la revitalización de aquél —que no la sobredimensión—, así como la constitucionalización de los espacios ciudadanos y de los poderes privados.

La existencia de una Constitución axiológica y valorativa, beligerante en suma, debería propiciar la desaparición de los llamados «juristas de Corte», los cuales se limitan a legitimar, con sus opiniones, decisiones políticas adoptadas por los poderes públicos correspondientes, o incluso por poderes privados, utilizando la conocida técnica de construir categorías dogmáticas, que únicamente sirven para justificar decisiones políticas previamente adoptadas, o para defender intereses concretos. Estas categorías no ayudan a la consolidación de éste nuevo constitucionalismo, sino que enmascaran u ocultan la realidad y pueden llegar a destruir o erosionar los propios principios constitucionales. $Y$ es que las categorías dogmáticas no pueden tener nunca por finalidad la justificación de decisiones políticas previamente adoptadas, tratándose más bien de crear otras que coadyuven, con sus propios elementos dinámicos intrínsecos, a transformar la realidad social $^{35}$.

35 Cfr., a este respecto, N. LUHMAN, Sistema jurídico y Dogmática jurídica, Madrid, 1983. 
Los poderes privados no pueden mantener dormidas las potencialidades del marco constitucional, el cual debe estar siempre activado, liderando tanto el sector público como el privado, pues estos no son compartimentos estancos. Pero además, los poderes privados no pueden ejercer, aunque sí participar en las mismas en la forma indicada anteriormente, las funciones constitucionalmente atribuidas a los poderes públicos, arrogándose incluso la titularidad del poder constituyente. $\mathrm{Y}$ es que no debemos olvidar que la actual crisis económica ha sido producida por la elite de los poderes privados, y que como consecuencia de la misma se ha generado un alto endeudamiento privado, muy superior al público, el deterioro de la competitividad, la escasa o nula innovación, la insuficiente inversión, o la irresponsabilidad fiscal y débil gobernanza corporativa ${ }^{36}$.

Y, finalmente, si bien es cierto que los poderes privados no deben estar sujetos a los mismos controles que los poderes públicos, salvo en el caso de que sean financiados por estos, también lo es que no pueden estar exentos de todo control, imponiéndose, por tanto, la necesidad de configurar nuevos mecanismos sobre aquellos, lo que ha de conducir a la exigencia de nuevas responsabilidades. Conviene tener en cuenta, precisamente, que la organización del poder — de todos los poderes añadiríamos en la actualidad — es el contenido indispensable de la Constitución, al servicio de la libertad e igualdad ciudadana. Si aquella en épocas pasadas únicamente se limitaba a la organización de los poderes públicos, ahora debe proceder también, aunque con otras técnicas y principios, a la organización de los poderes privados. De cualquier modo, más allá de la idea de control y, en consecuencia, de la reacción a posteriori contra los excesos, estaría la toma de conciencia de la responsabilidad que supone vivir en Constitución.

Title:

\section{CONSTITUTIONAL LAW AND THE CRISIS}

\section{Summary:}

I. Constitutional law and dialectical tensions. II. Constitutional law as common law. III. The fallacy of the current economic crisis. IV. Globalization and constitutional law: A) A new theory of the State. B) A new concept of representation. C) A new theory of the Constitution. D) A radical transformation of the system of sources of law. E) A new meaning of constitutional principles and

36 Así lo entiende A. PASCUAL-RAMSAY, «Un reto para la élite empresarial», El País, 5 de febrero de 2013. 
fundamental rights. F) A new system of relations between public authorities and between them and private powers.

\title{
Palabras clave:
}

Derecho constitucional; Crisis económica; Globalización; Estado social y democrático de Derecho.

\section{Keywords:}

Constitutional Law, Economic crisis, globalization, social and democratic state of law.

\section{Resumen:}

La actual crisis económica, originada por una serie de sujetos activos con la pretensión de ocupar determinados espacios públicos, es una de las consecuencias de la llamada «globalización de la miseria». La misma esta poniendo en tela de juicio el modelo democrático de las democracias occidentales, produciendo una crisis institucional más grave aún que la propia crisis económica. Ello conduce a la necesidad imperiosa de proporcionar respuestas normativas adecuadas, que requieren la utilización de nuevas categorías dogmáticas. A este respecto, el Derecho constitucional, como Derecho común del ordenamiento jurídico y como Derecho principial, se encuentra en una posición prevalente para llevar a cabo, en colaboración con las demás disciplinas jurídicas, todo ese proceso de reconstrucción dogmática que ha de conducir, necesariamente, a una constitucionalización de lo privado.

\begin{abstract}
:
The current economic crisis, caused by a series of active subjects with the aim of occupying certain public spaces, is one of the consequences of the "globalization of poverty». It is putting into question the democratic model of Western democracies, causing a constitutional crisis even worse than the economic crisis itself. This leads to the imperative to provide appropriate policy responses, requiring the use of new categories dogmatic. In this regard, constitutional law, and common law legal system and as principial law, is prevalent in a position to carry out, in collaboration with other legal disciplines, all that dogmatic reconstruction process that must lead necessarily, a constitution for the private.
\end{abstract}

